\title{
Altered Macrophage and Dendritic Cell Response in Mif-I- Mice Reveals a Role of Mif for Inflammatory-Th1 Response in Type 1 Diabetes
}

\author{
Yuriko Itzel Sánchez-Zamora, ${ }^{1}$ Imelda Juarez-Avelar, ${ }^{1}$ Alicia Vazquez-Mendoza, ${ }^{2}$ \\ Marcia Hiriart, ${ }^{3}$ and Miriam Rodriguez-Sosa ${ }^{1}$ \\ ${ }^{1}$ Unidad de Biomedicina, Facultad de Estudios Superiores (FES) Iztacala, Universidad Nacional Autónoma de México (UNAM), \\ 54090 Tlalnepantla, MEX, Mexico \\ ${ }^{2}$ Carrera de Optometría, FES-Iztacala, UNAM, 54090 Tlalnepantla, MEX, Mexico \\ ${ }^{3}$ Departamento de Neurodesarrollo y Fisiología, Instituto de Fisiología Celular, UNAM, 04510 Coyoacán, MEX, Mexico
}

Correspondence should be addressed to Miriam Rodriguez-Sosa; rodriguezm@campus.iztacala.unam.mx

Received 31 May 2016; Accepted 10 July 2016

Academic Editor: Jixin Zhong

Copyright (C) 2016 Yuriko Itzel Sánchez-Zamora et al. This is an open access article distributed under the Creative Commons Attribution License, which permits unrestricted use, distribution, and reproduction in any medium, provided the original work is properly cited.

\begin{abstract}
Macrophage migration inhibitory factor (Mif) is highly expressed in type 1 diabetes mellitus (T1DM). However, there is limited information about how Mif influences the activation of macrophages (M $\varphi$ ) and dendritic cells (DC) in T1DM. To address this issue, we induced T1DM by administering multiple low doses of streptozotocin (STZ) to Mif-/- or wild-type (Wt) BALB/c mice. We found that Mif-/- mice treated with STZ (Mif-/-STZ) developed lower levels of hyperglycemia, inflammatory cytokines, and specific pancreatic islet antigen- (PIAg-) IgG and displayed reduced cellular infiltration into the pancreatic islets compared to Wt mice treated with STZ (WtSTZ). Moreover, M $\varphi$ and DC from Mif-/-STZ displayed lower expression of MHC-II, costimulatory molecules CD80, CD86, and CD40, Toll-like receptor- (TLR-) 2, and TLR-4 than WtSTZ. These changes were associated with a reduced capacity of $\mathrm{M} \varphi$ and DC from Mif-/-STZ to induce proliferation in ovalbumin-specific T cells. All the deficiencies observed in Mif-/-STZ were recovered by exogenous administration of recombinant Mif. These findings suggest that Mif plays a role in the molecular mechanisms of $\mathrm{M} \varphi$ and DC activation and drives T cell responses involved in the pathology of T1DM. Therefore, Mif is a potential therapeutic target to reduce the pathology of T1DM.
\end{abstract}

\section{Introduction}

T1DM is an autoimmune-mediated disease characterized by selective destruction of insulin-producing pancreatic $\beta$ cells, resulting in the need for lifelong administration of exogenous insulin for patient survival [1], and represents 5$10 \%$ of all cases of diabetes $[2,3]$. The pathological condition begins with an autoimmune inflammatory process known as insulitis, which leads to leucocyte infiltration into the pancreatic islets of Langerhans, resulting in the autoimmune destruction of pancreatic $\beta$-cells [4]. Thus, the onset of T1DM is the result of the recognition of self-antigens due to molecular mimicry against infection with various viruses such as Coxsackie virus, $\beta$-cell cytotoxicity, or $\beta$-cell cytolysis
[5-7]. Consequently, molecules such as preinsulin, insulin, glutamate decarboxylase-65 (GAD-65), and islet antigen $2 \beta$ become recognized as self-antigens [8].

Different types of innate immune cells such as T cells, eosinophils, macrophages $(\mathrm{M} \varphi)$, and dendritic cells (DC) as well as proinflammatory cytokines and chemokines are present during insulitis $[4,9]$. The relationship between T1DM and high levels of inflammatory cytokines such as interleukin- (IL-) $1 \beta$ [10-14], interferon- (IFN-) $\gamma$ [15], tumor necrosis factor- (TNF-) $\alpha$ [16], IL-12 [17, 18], and macrophage migration inhibitory factor (Mif) [19-24] has been widely recognized.

Mif is a pleiotropic cytokine produced during the immune response by activated T cells, $\mathrm{M} \varphi, \mathrm{DC}$, and a variety 
of nonimmune cells and plays a pivotal role in the systemic inflammatory immune response by promoting the production of proinflammatory cytokines including TNF- $\alpha$ and IL6 , which are involved in inflammatory and autoimmune diseases such as septic shock [25], cancer [26], inflammatory bowel disease $[27,28]$, rheumatoid arthritis $[29,30]$, obesity [31, 32], and diabetes [33-35]. Moreover, Mif has recently been proposed as a diagnostic biomarker for autoimmune diseases [36] such as arthritis [37, 38], type 2 diabetes [35], and ulcerative colitis [39] in both animals and humans.

The pathogenic contribution of Mif to T1DM was demonstrated by showing that Mif mRNA expression was upregulated in splenic lymphocytes during the development of spontaneously diabetic nonobese diabetic (NOD) mice, as well as cyclophosphamide-treated NOD mice. Diabetes incidence was increased to $86 \%$ in NOD mice treated with recombinant Mif (rMif) protein, compared with the 55\% incidence observed in untreated control NOD mice [20]. Furthermore, studies performed using Mif-/- mice rendered diabetic by administering multiple low doses of streptozotocin (STZ) have shown that the absence of Mif affected several aspects of experimental T1DM, including initial immunopathological events and the production of proinflammatory and cytotoxic mediators, thereby interfering with both inflammation and tissue destruction [22].

All the results described above provide evidence that Mif plays a critical role in the pathogenesis of T1DM. However, the precise mechanism by which Mif promotes insulitis and the mechanism underlying its proinflammatory role remain unclear. The activities of Mif may reside at the levels of both the inductive and effector phases of the inflammatory response attributed to antigen-presenting cells.

Here, we analyzed the influence of Mif on $M \varphi$ and DC activation using an autoimmune diabetes model in which multiple low doses of STZ were administered to Mif-/and wild-type (Wt) mice (Mif-/-STZ and WtSTZ, resp.) in the BALB/c genetic background. As previously demonstrated Mif-/-STZ developed less severe hyperglycemia, reduced levels of IFN- $\gamma$ and TNF- $\alpha$, a smaller amount of pancreatic islet antigen- (PIAg-) specific IgG, and decreased cell infiltration into the pancreatic islets compared to WtSTZ. Interestingly, we found for the first time that $\mathrm{M} \varphi$ and $\mathrm{DC}$ from Mif-/-STZ displayed decreased expression of costimulatory molecules CD80, CD86, and CD40, as well as Toll-like receptor- (TLR-) 2, TLR-4, and major histocompatibility complex- (MHC-) II. Importantly, we demonstrated that due to diminished upregulation of costimulatory molecules, these cells exhibited a reduced capacity to induce proliferation and cytokine expression in cocultures with allogeneic ovalbumin- (OVA-) specific T cells. All deficiencies observed in Mif-/-STZ were reversed by exogenous rMif protein administration.

\section{Materials and Methods}

2.1. Ethics Statement. All experiments in this study were performed according to the guidelines in the Mexican Regulations on Animal Care (NOM-062-ZOO-1999, 2001) and were approved by the local Institutional Animal Care and Use Committee. All efforts were made to minimize animal suffering over the course of these studies.

2.2. Animals. Six- to 8-week-old male BALB/c mice were purchased from Harlan Laboratories (Mexico City, Mex.) and were maintained as a breeding colony in a pathogenfree environment at our animal facilities in accordance with institutional guidelines. Mif-/- mice were kindly provided by Dr. Abhay R. Satoskar (The Ohio State University, USA) and were maintained as breeding colonies for more than 10 generations in the $\mathrm{BALB} / \mathrm{c}$ genetic background on the Transgenic Mouse Core Facility at our institution. Genotyping of Mif-/- mice was routinely performed on DNA isolated from tail snips using a PCR procedure [40]. The PCR were performed using the following primers: Mif: forward $5^{\prime}$-AGACCACGTGCTTAGCTGAG-3' and reverse $5^{\prime}$ GCATCGCTACCGGTGGATAA-3'; Neomycin (Neo): forward $5^{\prime}$-ATTGAACAAGATGGATTGCAC- $3^{\prime}$ and reverse $5^{\prime}$-CGTCCAGATCATCCTGATC-3'. PCR for the amplification of Mif and NEO was performed by adding $100 \mathrm{ng}$ of the extracted DNA to $25 \mu \mathrm{L}$ of a reaction mixture that contained $18.4 \mu \mathrm{L}$ of distilled water, $2.5 \mu \mathrm{L}$ of $10 \mathrm{x}$ PCR buffer, $0.4 \mu \mathrm{L}$ of dNTPs $(10 \mathrm{mM}), 1.5 \mu \mathrm{L}$ of $\mathrm{MgCl}_{2}(25 \mathrm{mM}), 1 \mu \mathrm{L}$ of the forward and reverse primers, and $0.2 \mu \mathrm{L}$ (2.5 units) of Taq DNA polymerase (Ampliqon, Bioreagents and Molecular Diagnostics). The amplification protocol consisted of $5 \mathrm{~min}$ at $95^{\circ} \mathrm{C}, 35$ cycles of $95^{\circ} \mathrm{C}$ for $30 \mathrm{sec}, 58^{\circ} \mathrm{C}$ for $40 \mathrm{sec}$, and $72^{\circ} \mathrm{C}$ for $30 \mathrm{sec}$ and a final extension at $72^{\circ} \mathrm{C}$ for $5 \mathrm{~min}$. All PCR experiments were conducted with positive and negative controls. A PCR fragment of $200 \mathrm{bp}$, corresponding to Mif, or $500 \mathrm{bp}$, corresponding to NEO, was visualized to identify Wt or Mif-/- mice, respectively. The PCR products were analyzed by electrophoresis on a 1.5\% agarose gel and were viewed under UV light (Bio-Rad, USA).

2.3. Induction of T1DM. Mif-/- and Wt mice were deprived of food for $8 \mathrm{~h}$ before induction of diabetes via intraperitoneal (i.p.) injection of STZ at doses of $40 \mathrm{mg} / \mathrm{kg}$ of body weight, daily for five consecutive days (days 0-4) (Sigma-Aldrich, St. Louis, MO, USA). STZ was diluted in cold $0.01 \mathrm{M}$ citrate buffer ( $\mathrm{pH} 4.5$ ) and was used within $5 \mathrm{~min}$ of preparation, in accordance with a previously reported protocol [41]. Healthy mice from each group received i.p. injections of an equivalent volume of vehicle (citrate buffer) as negative controls.

2.4. Analysis of Blood Glucose, Serum Insulin, and Cytokine Levels. Blood samples were collected by tail snipping from Wt and Mif-/- mice that had been fasting for $6 \mathrm{~h}$. Samples were obtained once before STZ injection and 2, 4, and 8 weeks after STZ injection. Blood glucose levels were measured with a portable glucometer (Accu-Chek Sensor glucometer; Roche Diagnostics, Indianapolis, IN, USA). Mice with a glucose concentration exceeding $300 \mathrm{mg} / \mathrm{dL}$ were considered to have T1DM. Blood was collected and centrifuged at $1300 \times \mathrm{g}$, and the serum levels of Mif (Neobiolab, USA), IL-12, IFN- $\gamma$, IL17, IL-4, IL-13 (PeproTech, Mex), and insulin (Lincoln, St. Charles, MO, USA) were determined via ELISA according to the manufacturer's instructions. 
2.5. Pancreatic Islets Antigen (PIAg) Isolation. PIAg islets were obtained from healthy Wt mice as described below. After isolation, the islets were lysed by five freeze-thaw cycles followed by sonication (six $60-\mathrm{Hz}$ cycles for $1 \mathrm{~min}$ each) on ice. After centrifugation ( $\left.10000 \mathrm{~g}, 15 \mathrm{~min}, 4^{\circ} \mathrm{C}\right)$, supernatants were collected and filtered through a $0.2 \mu \mathrm{m}$ membrane (Corning, Cambridge, MA, USA). The protein concentration was determined using the Lowry method [42], and PIAg aliquots were stored at $-70^{\circ} \mathrm{C}$ until use.

2.6. Analysis of IgG Antibody Production. Serum samples were analyzed for the levels of pancreatic islet-specific Th1associated IgG2a and Th2-associated IgG1 antibodies by ELISA. Briefly, 96-well ELISA plates (Costar) were coated with $100 \mu \mathrm{L} /$ well soluble PIAg in Tris buffer, $\mathrm{pH}$ 7.8. The plates were incubated overnight at $4^{\circ} \mathrm{C}$. Then, the wells were washed thoroughly with phosphate-buffered saline (PBS) containing $0.05 \%$ Tween-20 (PBS-Tween; Merck, France) and were blocked with PBS supplemented with $1 \%$ bovine serum albumin (PBS-BSA; Sigma-Aldrich) for one hour at room temperature (RT). The serum samples were diluted $1: 100$, followed by serial dilution of each sample (in PBSBSA) from healthy or STZ-treated Wt or Mif-/- mice. The plates were then incubated at $4^{\circ} \mathrm{C}$ overnight. After extensive washing with PBS-Tween, the samples were incubated for $45 \mathrm{~min}$ at RT with isotype-specific peroxidase-labeled goat anti-mouse antibodies (anti-IgG1 and anti-IgG2a at 1/1000 dilutions; Zymed, San Francisco, CA, USA). Then, the plates were washed, and immunoreactivity was detected with ABTS solution (Zymed). The results were expressed as endpoint titers based on optical density.

2.7. Histopathology. Pancreatic tissues from Wt and Mif-/mice healthy or injected with STZ were removed, fixed overnight in $4 \%$ formaldehyde, and embedded in paraffin blocks. Afterwards, 5 to $7 \mu \mathrm{m}$ transverse sections of pancreatic tissue were sliced from the paraffinized tissue blocks, mounted on slides, and subsequently stained with eosinhematoxylin (E\&H; Sigma-Aldrich). For each mouse, one histological containing 1-3 nonsuccessive slices was scored for infiltration as previously described [43] according to the following scale: grade 0 (no insulitis) $=0 \%$ infiltration within the islets; grade 1 (peri-insulitis) $=1-10 \%$ infiltration; grade 2 (moderate insulitis) $=11-<50 \%$ infiltration; grade 3 (severe insulitis) $=>50 \%$ infiltration; or grade 4 (complete insulitis) $=$ extensive infiltration with few or no detectable pancreatic islet cells. Using an Olympus BX51 microscope (Olympus America, Melville, NY, USA) equipped with a digital video camera, 30 islets of Langerhans were evaluated per mouse.

2.8. Cell and Pancreatic Islet Isolation. Spleen and pancreatic islet cells from WtSTZ and Mif-/-STZ were collected after $0,2,4$, and 8 weeks of injection with STZ and stained for flow cytometry analysis. Briefly, the spleen was removed under sterile conditions, and spleen cells were obtained by mincing and filtering the tissue, followed by washing and suspension in DMEM culture medium supplemented with $10 \%$ fetal bovine serum, 100 units of penicillin/streptomycin, $2 \mathrm{mM}$ glutamine, and $1 \%$ nonessential amino acids (all from
GIBCO, BRL, Grand Island, NY, USA). Spleen cells were suspended at $5 \times 10^{6}$ cells $/ \mathrm{mL}$ in the same medium. The pancreas was also removed under sterile conditions, and pancreatic islets were isolated using the collagenase method as previously described [44]. Briefly, the pancreas was removed and cut into small pieces (approximately $3 \mathrm{~mm}$ in size). The tissue was subsequently incubated in collagenase $(0.3 \mathrm{mg} / \mathrm{mL}$; Roche Diagnostics Corp., Indianapolis, IN, USA) for 10 minutes at $37^{\circ} \mathrm{C}$ in a total of $1 \mathrm{~mL}$ of digestion solution under constant shaking and intermittent vortexing. Islets were subsequently washed several times in HBSS containing BSA $(5 \mathrm{mg} / \mathrm{mL})$ and were hand-picked under a dissecting microscope. Islets were dispersed into single cells by suspension in trypsin-EDTA (GIBCO, BRL) and passage through a siliconized Pasteur pipette. Then, the cells were incubated at $37^{\circ} \mathrm{C}$.

2.9. Flow Cytometry Analysis. Cells from the spleen or pancreas obtained as described above were then used for flow cytometry analysis. In brief, cells were washed in flow cytometry wash solution (Dulbecco's PBS containing $1 \%$ FCS and $0.05 \%$ sodium azide), followed by incubation with allophycocyanin- (APC-) conjugated anti-F4/80 and anti-CD1lc antibodies for differentiation of $\mathrm{M} \varphi$ and DC, respectively. Then, the selected cells were incubated in 3\% BSA-PBS containing a phycoerythrin- (PE-) labeled antiCD80, anti-CCR5, or anti-TLR-4 antibody or a fluorescein isothiocyanate- (FITC-) labeled anti-CD86, anti-CD40, anti-MHC-II, or anti-TLR-2 antibody (all antibodies from Biolegend, San Diego, CA, USA) at $4^{\circ} \mathrm{C}$ for $30 \mathrm{~min}$. After incubation, the cells were washed several times in buffer, fixed in 1\% paraformaldehyde (Sigma-Aldrich), and stored at $4^{\circ} \mathrm{C}$ in the dark, followed by analysis using a FACSCalibur flow cytometer and CellQuest software (Becton Dickinson, Franklin Lakes, NJ, USA).

2.10. Coculture of Macrophages with Spleen Cells. Coculture of $\mathrm{M} \varphi$ with naive spleen cells was performed as follows. Adherent $\mathrm{M} \varphi$ among peritoneal exudate cells (PECs) from healthy or 8 weeks after STZ-treatment Wt or Mif-/- mice were obtained. Briefly, the $\mathrm{M} \varphi$ density was adjusted to $5 \times$ $10^{6}$ cells $/ \mathrm{mL}$, and the cells were plated $(100 \mu \mathrm{L})$ in 96-well flat-bottom plates (Costar, Cambridge, MA, USA). Three hours later, the PECs were washed three times with warm sterile PBS to remove nonadherent cells, and $10 \mu \mathrm{g}$ of OVA (Worthington, USA) in $100 \mu \mathrm{L}$ of DMEM supplemented media was added. Three hours later, adherent $\mathrm{M} \varphi$ were washed three times with warm sterile DMEM to remove excess OVA that had not been phagocytosed. Spleen cells from OVA-transgenic mice were obtained as previously described [45], suspended at $1 \times 10^{6}$ cells $/ \mathrm{mL}$, and added $(100 \mu \mathrm{L})$ to PECs at a ratio of $1 \mathrm{M} \varphi: 5$ spleen cells. The cocultures were maintained at $37^{\circ} \mathrm{C}$ in $5 \% \mathrm{CO}_{2}$ for 5 days. Then, $[3 \mathrm{H}]$-thymidine $(185 \mathrm{GBb} / \mathrm{mmol}$ activity, Amersham, $\mathrm{UK}$ ) was added at $0.5 \mu \mathrm{Ci} /$ well, and the cells were incubated for a further $18 \mathrm{~h}$. The cells were harvested using a 96-well harvester (Tomtec, Toku, Finland) and then counted using a microplate counter (Trilux, Toku, Finland). The values are presented as counts per minute (CPM) from triplicate wells. 


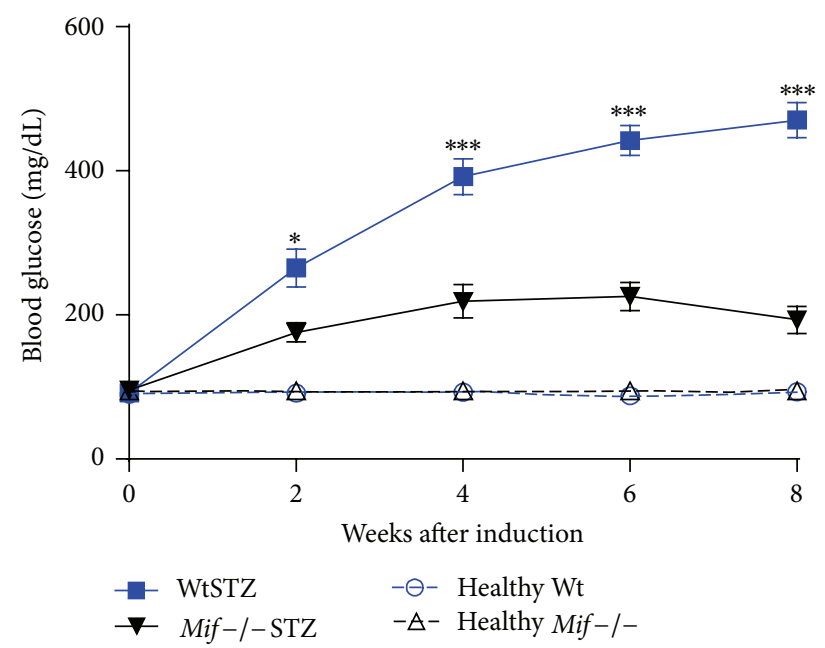

(a)

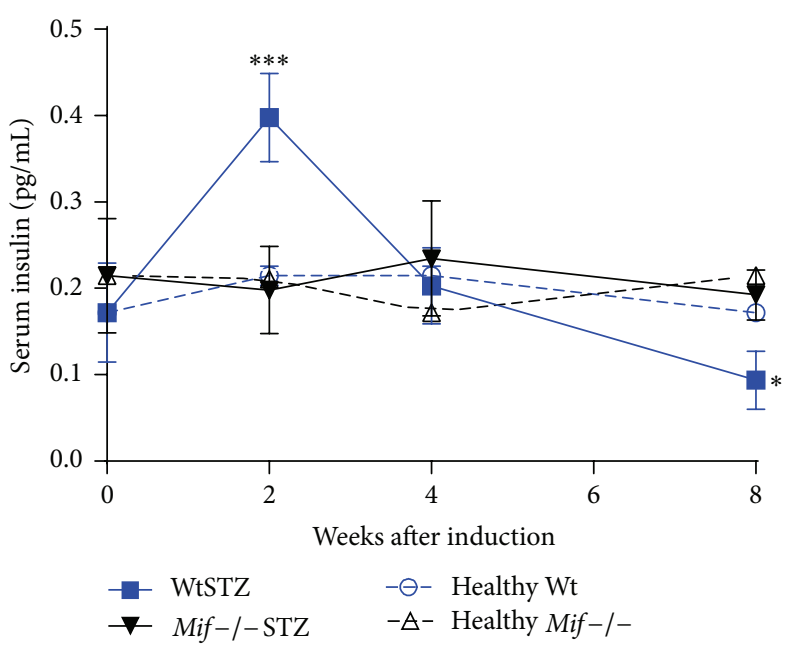

(b)

Figure 1: Mif-/- mice developed less severe hyperglycemia than Wt mice after type 1 diabetes mellitus induction. Blood glucose (every 2 weeks) (a) and serum insulin (0,2, and 8 weeks) (b) levels were monitored as described in Section 2 in Wt ( $\mathbf{\square})$ and Mif-/- ( $\mathbf{\nabla})$ mice after STZ administration; as controls, healthy Wt $(O)$ or healthy Mif-l- $(\Delta)$ mice were plotted as well. All data are representative of three independent experiments and are expressed as the means \pm SE $(n=$ at least $5-7$ animals per group/time point $) .{ }^{*} p<0.05,{ }^{* * *} p<0.001$, GraphPad Prism software 6 .

2.11. Mif Reconstitution. To establish the Mif levels under conditions of T1DM, the serum Mif levels were determined weekly until 8 weeks after STZ treatment in WtSTZ. Mif-/-STZ received similar concentrations of rMif (R\&D Systems, USA) to the Mif levels observed in WtSTZ to emulate physiological conditions in WtSTZ. Briefly, Mif-/mice received i.p. injection of STZ together with $500 \mathrm{pg}$ of rMif in $100 \mu \mathrm{L}$ of saline solution as a vehicle. Upon STZ treatment, Mif-/- mice received an i.p. injection of rMif every three days at the following doses: $850 \mathrm{pg}$ on week 1 ; $1280 \mathrm{pg}$ on week 2; $1292 \mathrm{pg}$ on week 3; $1305 \mathrm{pg}$ on week 4; $4300 \mathrm{pg}$ on week 5; $7300 \mathrm{pg}$ on week 6; and, finally, $13200 \mathrm{pg}$ on week 7. Other Mif-/-STZ mice were injected with an equivalent volume of saline solution $(100 \mu \mathrm{L})$ as controls.

2.12. Statistical Analysis. Comparisons between $\mathrm{Wt}$ and Mif-/- mice that were healthy or treated with STZ were performed using either Student's unpaired $t$-test or ANOVA followed by Turkey's multiple comparisons test for data that displayed a normal distribution. $p$ values less than 0.05 were considered significant and were designated as ${ }^{*} p<0.05$, ${ }^{* *} p<0.01$, or ${ }^{* * *} p<0.001$. All data were analyzed using GraphPad Prism 6 software (San Diego, CA, USA).

\section{Results}

3.1. Mif-/- Mice Developed Less Severe Hyperglycemia Than Wt Mice after STZ Administration. We first investigated the clinical effects of STZ on Mif-/- and Wt mice. Our data demonstrated that Wt mice rapidly developed hyperglycemia after STZ administration. These mice sustained high blood glucose levels from week $2(281.7 \pm 16 \mathrm{mg} / \mathrm{dL})$ until week 8 of STZ administration ( $470.5 \pm 24 \mathrm{mg} / \mathrm{dL}$ ) (Figure 1(a), WtSTZ: squares). In contrast, hyperglycemia developed gradually in
Mif-/-STZ. The blood glucose level of Mif-/-STZ peaked at $219 \pm 23 \mathrm{mg} / \mathrm{dL}$ on week 4 , and the blood glucose level in some mice decreased between weeks 6 and 8 (226 \pm 15 and $182 \pm$ $16 \mathrm{mg} / \mathrm{dL}$, resp.) (Figure 1(a), Mif-/-STZ: inverted triangles). This observation suggested that a slight recovery of the glucose response may occur in Mif-/-STZ at approximately week 8 of STZ treatment.

WtSTZ showed a peak blood insulin level at 2 weeks after STZ treatment, and after the sixth and eighth weeks of treatment, their blood insulin levels were significantly lower than those of healthy Wt mice (Figure 1(b), WtSTZ: squares with solid line; Wt mice: white circles with dotted line). Interestingly, Mif-/-STZ showed no significant changes in insulin levels compared to healthy Mif-/- or Wt mice over the course of the experiment (Figure 1(b), Mif-/-STZ: inverted triangles with solid line; healthy Mif-/- mice: white triangles with dotted line).

\subsection{Mif-/- Mice Produced Lower Proinflammatory Cytokine} Levels Than Wt Mice after T1DM Induction. We measured the serum levels of proinflammatory and anti-inflammatory cytokines in Wt and Mif-/- mice after STZ administration. As expected, the WtSTZ displayed gradually increasing serum levels of inflammatory cytokines such as Mif, IL12, and IFN- $\gamma$ (Figures 2(a), 2(b), and 2(c), resp., WtSTZ: squares) between 2 and 8 weeks after T1DM induction. The level of the proinflammatory cytokine IL-17 was significantly increased at 8 weeks after T1DM induction in WtSTZ (Figure 2(d), squares). In contrast, Mif-/-STZ displayed significantly lower serum levels of Mif, IL-12, IFN- $\gamma$, and IL-17 than WtSTZ (Figures 2(a), 2(b), 2(c), and 2(d), resp.; Mif-/-STZ: inverted triangles).

The serum levels of the anti-inflammatory cytokine IL4 were significantly lower in WtSTZ (squares) than in 


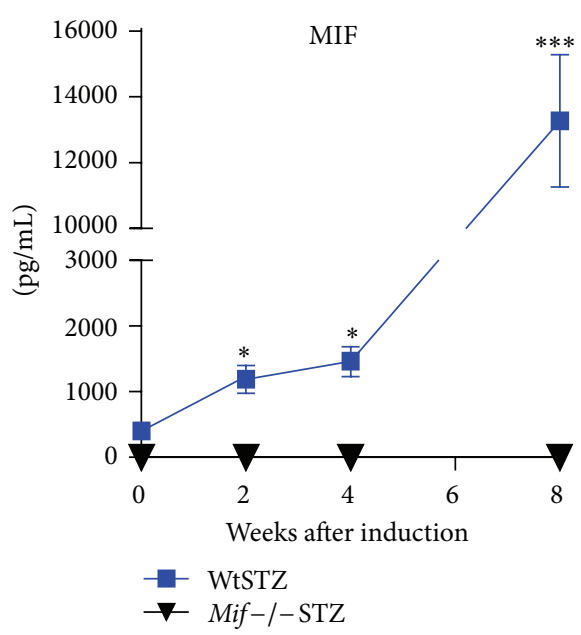

(a)

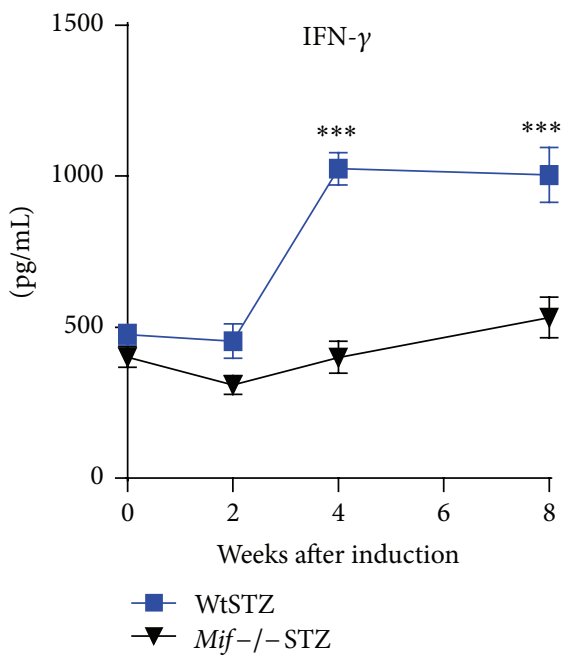

(c)

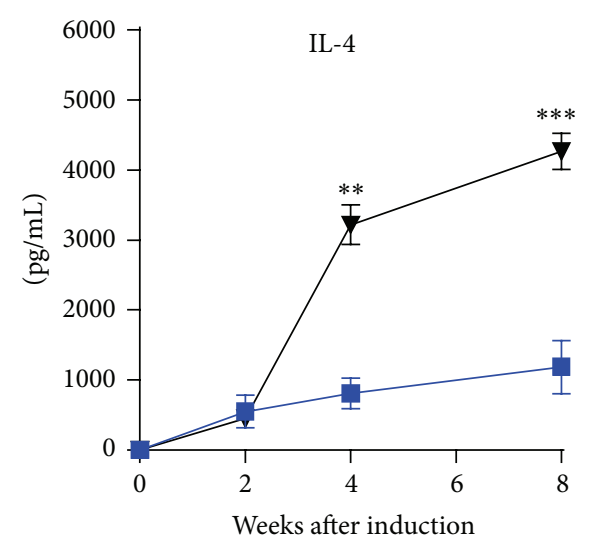

WtSTZ

Mif-/-STZ

(e)

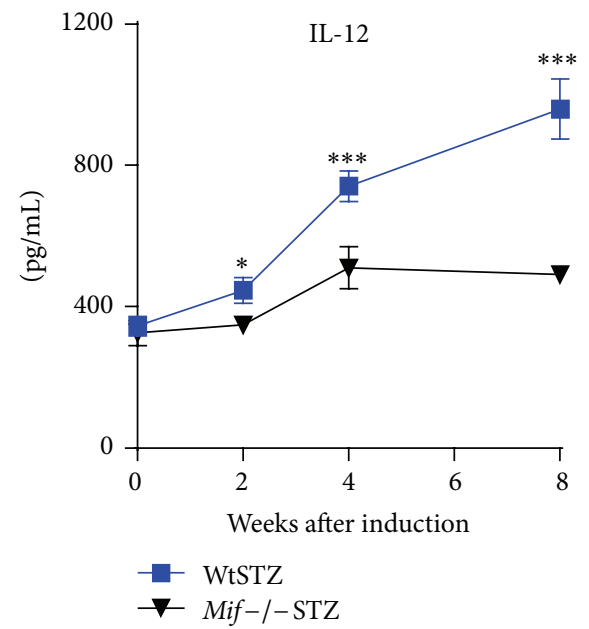

(b)

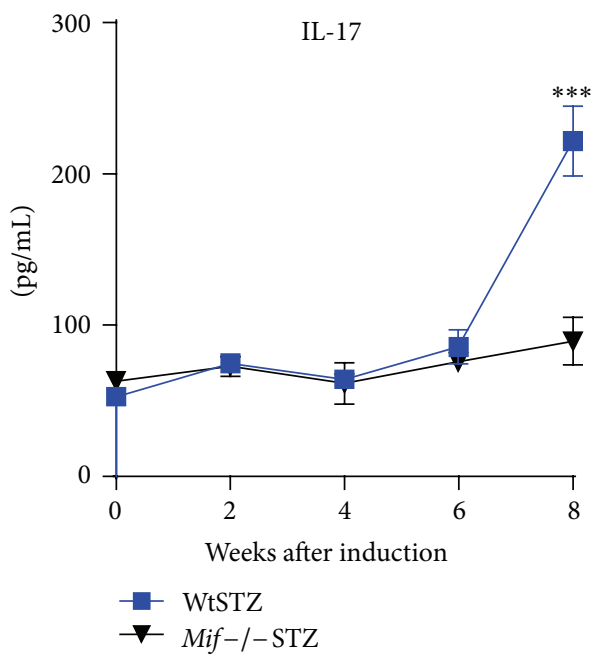

(d)

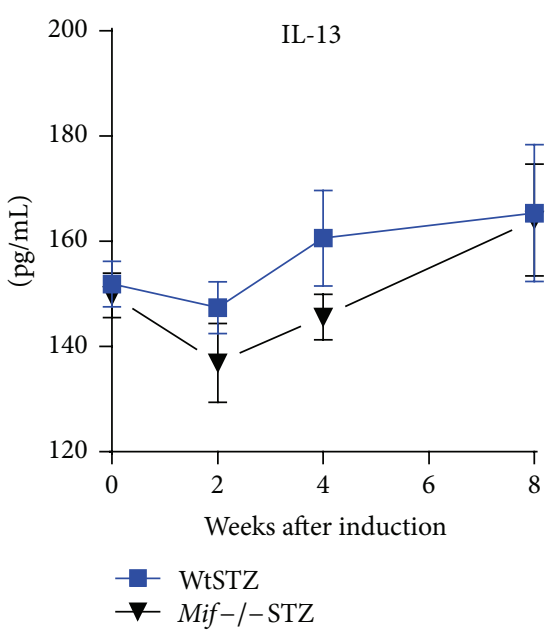

(f)

FIGURE 2: Mif deficiency prevents the elevation of proinflammatory cytokine production. The levels of Mif (a), IL-12 (b), IFN- $\gamma$ (c), IL-17 (d), IL-4 (e), and IL-13 (f) in the sera from Wt ( $\mathbf{-})$ and Mif-/- ( $)$ mice at $0,2,4$, and 8 weeks after STZ administration were measured via enzyme-linked immunosorbent assay (ELISA) in triplicate, as indicated in Section 2. Data are expressed as the means \pm SE ( $n=$ at least $5-7$ mice per group/time point). ${ }^{*} p<0.05,{ }^{* *} p<0.01$, or ${ }^{* * *} p<0.001$, GraphPad Prism software 6. 
TABLE 1: Assessment of the extent of leukocyte infiltration into pancreatic islets of WT and Mif-/- mice at 8 weeks after STZ administration.

\begin{tabular}{lccc}
\hline Groups & $\begin{array}{c}\text { Number of } \\
\text { islets }\end{array}$ & $\begin{array}{c}\text { Infiltrated } \\
\text { islets }\end{array}$ & $\begin{array}{c}\text { Islets that lost circular } \\
\text { morphology }\end{array}$ \\
\hline Wt & 100 & ND & ND \\
WtSTZ & 100 & 100 & 65 \\
Mif-/- & 100 & ND & ND \\
Mif-/-STZ & 100 & 33 & 25 \\
\hline
\end{tabular}

ND: none detected; Wt: wild-type.

Mif-/-STZ (inverted triangles) (Figure 2(e)). No differences in the serum IL-13 levels were found between WtSTZ and Mif-/-STZ (Figure 2(f)).

3.3. Mif-/- Mice Showed Reduced Pancreatic Islet Damage and Cellular Infiltration Compared to Wt Mice after T1DM Induction. To confirm that STZ reached its target, Wt and Mif-/- mice were treated with a single high dose of STZ $(150 \mathrm{mg} / \mathrm{kg})$. The toxic effect of high-dose STZ was similar between Wt and Mif-/- mice (Supplementary Figure 1 in Supplementary Material available online at http://dx.doi.org/10.1155/2016/7053963). In both experimental groups, the toxic effect of STZ was present, and the high dose of STZ destroys the insulin-producers beta cells, leading to acute nonimmune-mediated diabetes; in contrast the multiple low doses of STZ at $40 \mathrm{mg} / \mathrm{Kg}$, daily for five consecutive days, require participation of immune-inflammatory events for T1DM development [41].

To assess the damage to $\beta$ cells in a model of T1DM induced by multiple low doses of STZ, we sacrificed the mice at 8 weeks after T1DM induction and removed the pancreas for H\&E staining and histological analysis. We assessed the number and size of normal and infiltrated pancreatic islets in each slide for the experimental and healthy mice. Thirty pancreatic islets were quantified per experimental group.

Islets from healthy Wt and Mif-/- mice had a round morphology and well-defined borders without cellular infiltration (Figures 3(a) and 3(c)). As expected, the pancreas from WtSTZ showed fewer and smaller islets than those from healthy Wt mice. Additionally, evident cellular infiltration led to the breakdown of islet morphology in the pancreas of WtSTZ (Figure 3(b)). In contrast, partial islet damage (Figure 3(d)) and no significant reduction in islet number or size were observed in Mif-/-STZ compared to WtSTZ (Table 1).

As shown in Figure 3(e), Mif-/- mice at 8 weeks after STZ administration displayed marked reductions in both invasive insulitis (insulitis grades 3 and 4) and mild periinsulitis (insulitis grade 2) in pancreatic islets compared to WtSTZ. Thus, pancreatic islets from Mif-/-STZ had reduced damage associated with reduced leucocyte infiltration compared to pancreatic islets from WtSTZ. These results demonstrated that STZ administration triggers $\beta$-cell destruction followed by insulin deficiency and hyperglycemia in Wt mice. Although STZ reached the pancreatic islets in Mif-/- mice, Mif-/-STZ exhibited minor damage compared to WtSTZ.
3.4. Mif-/- Mice Showed Lower Levels of Specific Pancreatic Islet Antibodies Than Wt Mice after T1DM Induction. In T1DM, the immune system targets self-antigens within pancreatic islets and destroys the inhabiting insulin-secreting $\beta$ cells. Therefore, autoantibody detection serves as a predictive factor for the onset of diabetes in both humans and mice $[46,47]$.

To investigate how Mif contributes to autoantibody production in T1DM, the serum levels of pancreatic islet-specific IgG2a and IgG1 antibodies were determined in Wt and Mif-/- mice after 2, 4, and 8 weeks after STZ administration. WtSTZ produced high levels of IgG2a at all time points analyzed (Figure 4(a)) and IgG1 only at week 8 (Figure 4(b)). Importantly, Mif-/-STZ mice displayed significantly lower levels of both IgG2a and IgG1 than WtSTZ (Figures 4(a) and 4(b), resp.), suggesting suppressed development of an adaptive immune response. These findings suggest that Mif modulates the incidence and severity of diabetes by favoring the development of autoantibodies in T1DM.

3.5. Splenic M $\varphi$ and DC from Mif-/-STZ Mice Expressed Lower Levels of Costimulatory Molecules Than Those from WtSTZ Mice. We showed that the reduced severity of T1DM in Mif-/-STZ is associated with decreased pancreatic islet damage and diminished adaptive immune responses. To determine whether this phenotype could be related to the degree of activation of antigen-presenting cells, we characterized the expression of the costimulatory molecules CD80, CD86, and MHC-II and of the receptors TLR- 2 and TLR-4 in $\mathrm{M} \varphi$ and DC from the spleen and pancreas of Mif-/- and Wt mice after $0,2,4$, and 8 weeks of STZ administration.

In cells isolated from the spleen, the percentages of CD80-, CD86-, MHC-II-, TLR2-, and TLR4-expressing M $\varphi$ $\left(\mathrm{F} 4 / 80^{+}\right)$were similar between healthy Mif-/- and Wt mice (Figures 5(a), 5(b), 5(c), 5(d), and 5(e), resp., at time 0 post-STZ administration, right panel). Interestingly, upon STZ administration, Mif-/- mouse $M \varphi$ showed impaired activation, characterized by reduced expression of CD80, CD86, MHC-II, TLR-2, and TLR-4, compared with $\mathrm{M} \varphi$ from WtSTZ mice (Figures 5(a), 5(b), 5(c), 5(d), and 5(e), resp.).

Similarly, DCs $\left(\mathrm{CD}_{11 \mathrm{c}^{+}}\right)$isolated from the spleen of Mif-/-STZ mice expressed lower levels of CD80, CD86, and MHC-II at 4 through 8 weeks after STZ administration (Figures 6(a), 6(b), and 6(c), resp.), whereas the expression of TLR-2 and TLR- 4 in DCs was reduced at 4 weeks in Mif-/-STZ compared to WtSTZ (Figures 6(d) and 6(e), resp.).

3.6. Pancreatic $M \varphi$ and DC from Mif-/-STZ Mice Express Lower Levels of Costimulatory Molecules Than Those from WtSTZ Mice. To investigate the role of Mif in the activation of APCs in the pancreas, we determined MHC-II and costimulatory molecule expression in $\mathrm{M} \varphi$ and $\mathrm{DC}$ in the pancreas of Mif-/-STZ and WtSTZ mice. $\mathrm{M} \varphi$ from Mif-/-STZ expressed lower levels of CD80 and CD86 from 4 through 8 weeks after STZ administration (Figures 7(a) and 7 (b), resp.). Alternatively, reduced expression of MHC-II, TLR-2, and TLR- 4 was detected earlier, from 2 weeks until 8 weeks after STZ treatment (Figures 7(c), 7(d), and 7(e), resp.). 


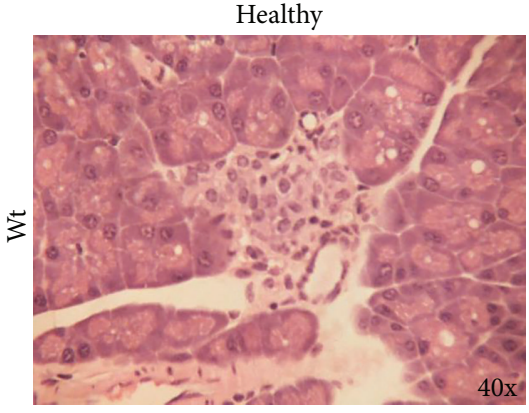

(a)

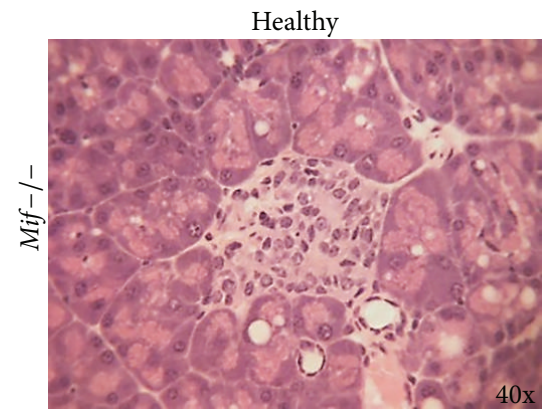

(c)

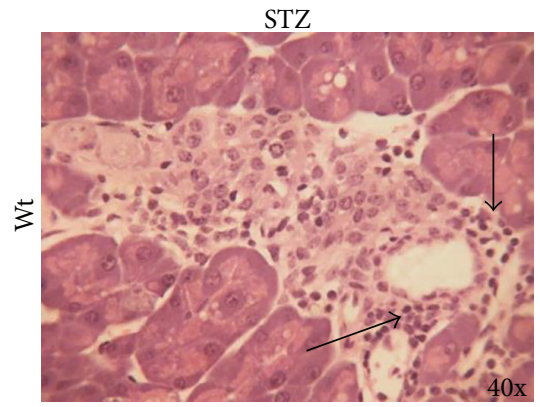

(b)

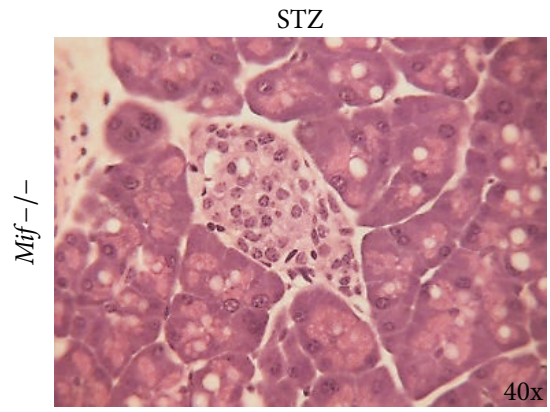

(d)

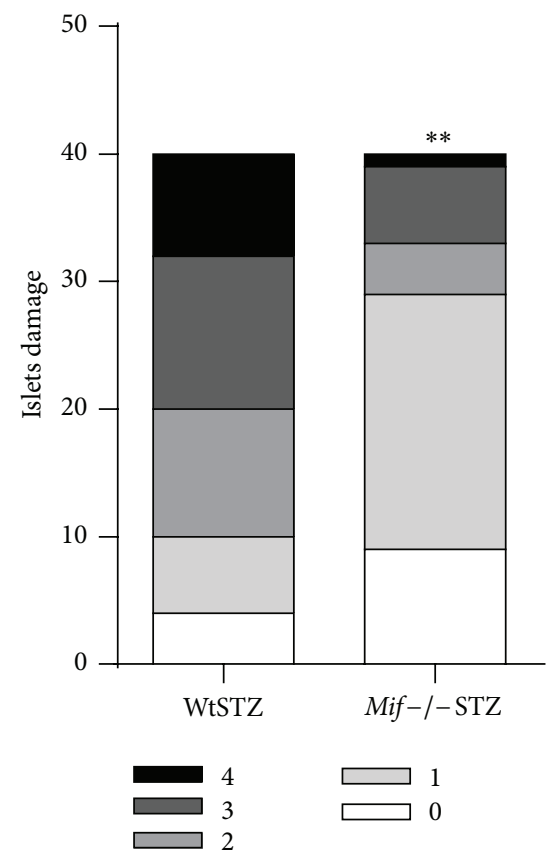

(e)

FIGURE 3: Mif-/- mice conserve their healthy anatomy and exhibit limited cellular infiltration into pancreatic islets after STZ administration. Pancreases isolated from Wt or Mif-/- mice were examined via histological analysis of eosin-hematoxylin (E\&H) staining to establish the number of pancreatic islets and to determine lymphocyte infiltration (arrowhead in (b)) at 8 weeks after STZ administration. Pancreatic islets from healthy Wt mice (a); Wt mice treated with STZ, WtSTZ (b); healthy Mif-/- mice (c), and Mif-/- mice treated with STZ, Mif-/-STZ (d). Compilation of infiltration stages in the pancreas of Wt and Mif-/- mice after STZ administration (e). Pancreatic islets were scored using the following scale: grade 0 (no insulitis) $=0 \%$ infiltration; grade 1 (peri-insulitis) $=1-10 \%$ infiltration; grade 2 (moderate insulitis) $=$ $11-<50 \%$ infiltration; grade 3 (severe insulitis) $=>50 \%$ infiltration; or grade 4 (complete insulitis) $=$ complete infiltration. We counted $30-40$ islets per experiment using six mice per experimental group, depending on the number of islets that were present in the sections. All data are representative of two independent experiments, $n=12$ from two experiments. ${ }^{* *} p<0.01$, GraphPad Prism software 6 . 


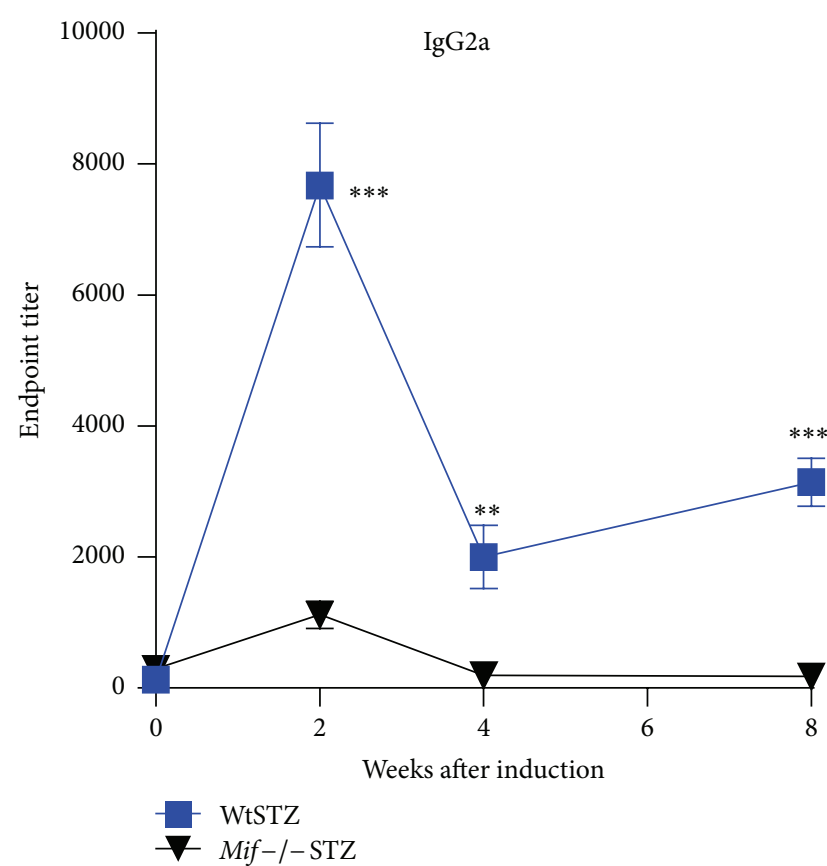

(a)

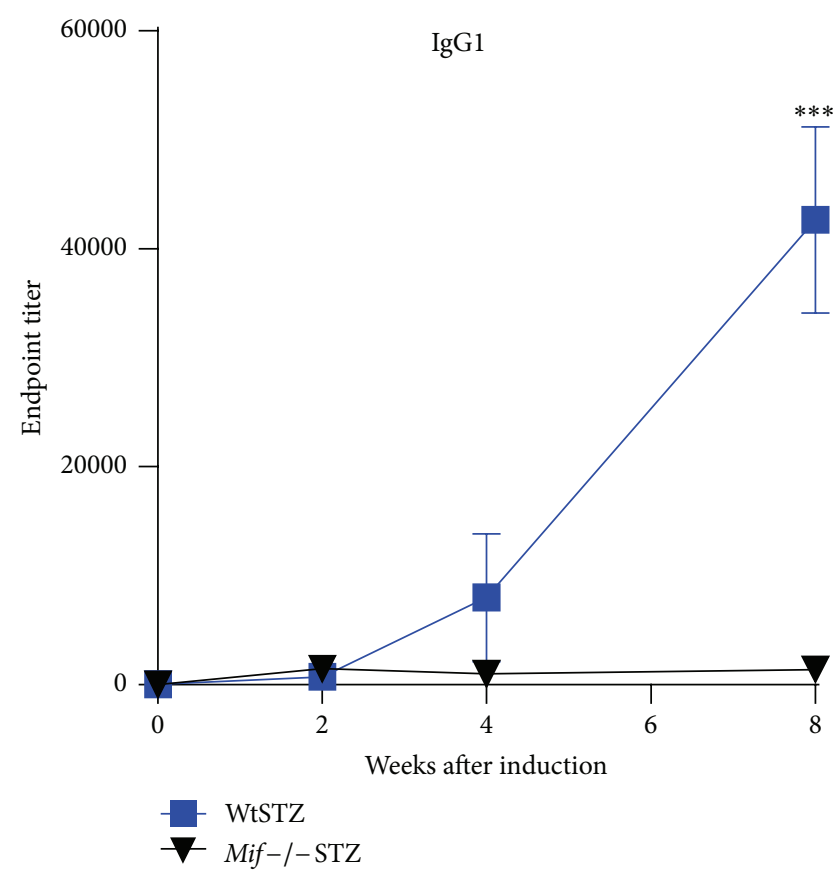

(b)

FIGURE 4: Kinetics of antibody responses in type 1 diabetes mellitus models induced by low-dose STZ. Specific production of IgG2a (a) and IgG1 (b) antipancreatic islet antigen antibodies. Sera from Wt ( $\mathbf{})$ and Mif-/- mice ( $\boldsymbol{\nabla})$ at weeks $0,2,4$, and 8 after STZ administration were processed by ELISA, using pancreatic islets antigen (PIAg) as the source of specific antigen as indicated in Section 2. Data are expressed as the mean reciprocal endpoint titer \pm SEM. Five to six animals were analyzed in each group. The data shown are representative of one out of three identical experiments with similar results. Mann-Whitney $U$ test. ${ }^{* *} p<0.01,{ }^{* * *} p<0.001$, GraphPad Prism software 6.

Moreover, DC from Mif-/-STZ mice displayed reduced CD80 at 4 to 8 weeks (Figure 8(a)), CD86 at all time points analyzed (Figure $8(\mathrm{~b})$ ), and reduced TLR-2 and TLR4 expression at 4 weeks and 2 weeks, respectively, compared to DCs from WtSTZ (Figures 8(d) and 8(e), resp.). No significant differences in MHC-II expression were detected (Figure 8(c)).

3.7. F4/80 ${ }^{+}$Macrophages and $C D 11 b^{+}$Monocytes Obtained from Mif-/-STZ Show Impaired Capacity to Induce Spleen Cell Proliferation. The ability of $\mathrm{M} \varphi$ to activate $\mathrm{T}$ cells was investigated using OVA-transgenic $\mathrm{T}$ cell cocultures. $\mathrm{M} \varphi$ were collected from Wt or Mif-/- mice treated or untreated for 8 weeks with STZ. As shown in Figure 9(a), after priming the cells with OVA in vitro, $\mathrm{M} \varphi$ from Mif-/-STZ mice induced less $\mathrm{T}$ cell proliferation in response to OVA than $\mathrm{M} \varphi$ from WtSTZ. A similar trend was observed in cocultures of $\mathrm{CD}_{11 b^{+}}$cells from Mif-/-STZ and OVA-transgenic T cells (Figure 9(b)). These data suggest a role of Mif in promoting $M \varphi$ activation, which in turn induces specific $\mathrm{T}$ cell proliferation, particularly in this experimental T1DM model.

3.8. Mif Reconstitution in STZ-Treated Mif-/- Mice Promotes Hyperglycemia and Reestablishes the Production of Proinflammatory Cytokines in This T1DM Model. The systemic levels of Mif were reconstituted in Mif-/-STZ mice during the course of T1DM, as described in Section 2. Mif-/-STZ that received rMif (Mif-/-STZ+rMif) displayed blood glucose levels similar to those in WtSTZ during the first six weeks after STZ treatment. However, at 8 weeks after STZ treatment, the glucose levels were not increased in Mif-/-STZ+rMif compared to WtSTZ (Figure 10(a)).

Comparable serum levels of the cytokines IL- 6 and IL12 were observed between Mif-/-STZ+rMif and WtSTZ during the first 6 weeks after STZ treatment. However, the levels of these inflammatory cytokines significantly decreased in Mif-/-STZ+rMif mice at 8 weeks after STZ treatment compared to WtSTZ (Figures 10(b) and 10(d)). Interestingly, the serum levels of TNF- $\alpha$ from Mif-/-STZ+rMif were higher than those of WtSTZ at all time points analyzed (Figure 10(c)). These results confirm that Mif acts as a powerful inducer of proinflammatory cytokines involved in the development of experimental T1DM.

\section{Discussion}

Currently, there is no doubt that Mif is a key molecule that promotes proinflammatory immune responses [48]. This proinflammatory property of Mif contributes to developing protective inflammatory-Thl immune response in different models of parasitic diseases [49]. In contrast the same proinflammatory property of Mif participates in the pathogenesis of many inflammatory diseases [50]. In line with the last one, recently it has been established that high blood levels of Mif are associated with human T1DM, similar to the findings in experimental mouse models of T1DM [20, 21, 24, 51]. 


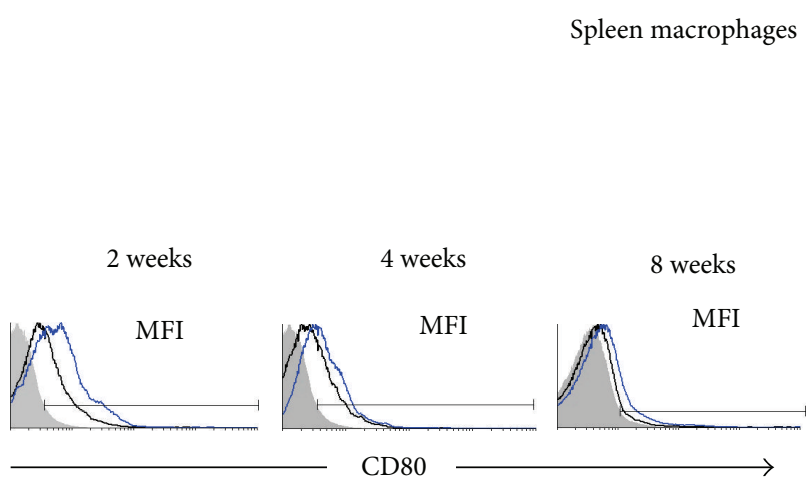

(a)

Spleen macrophages

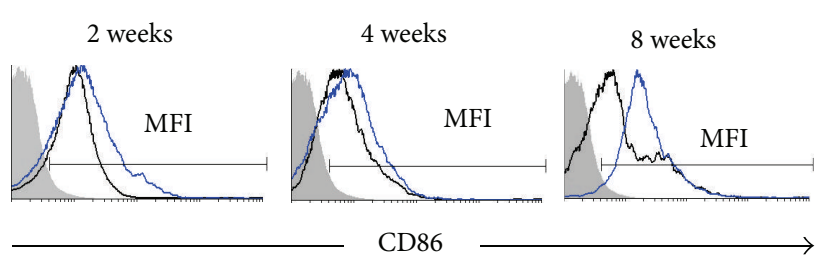

(b)

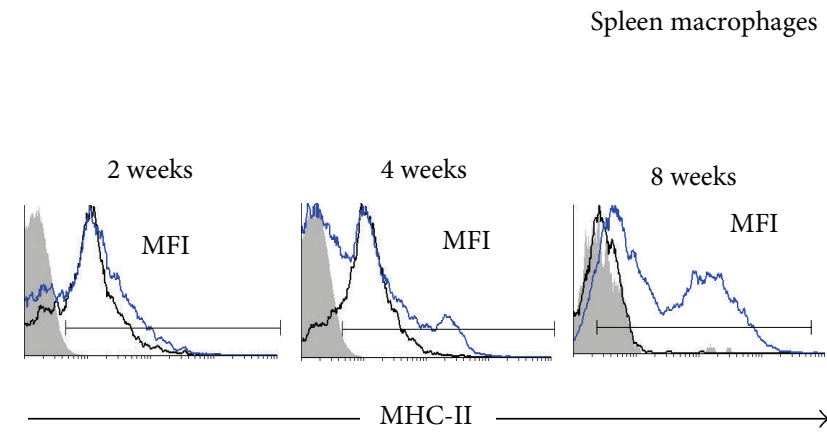

(c)

Spleen macrophages

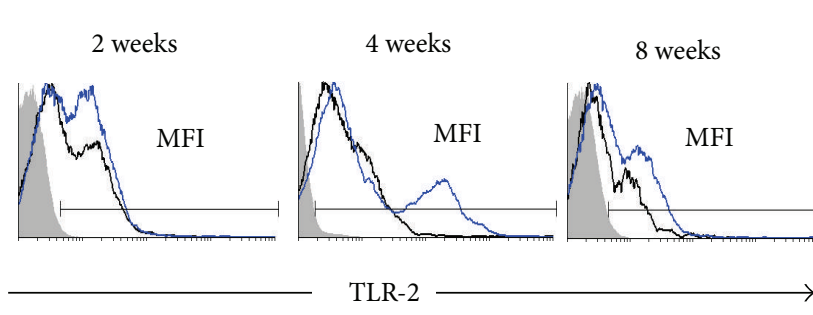

(d)
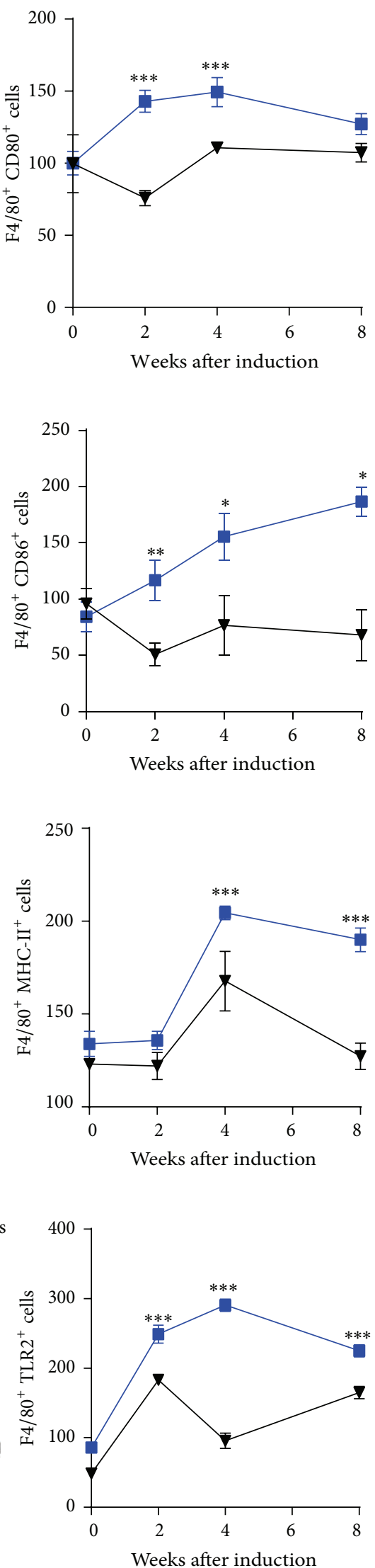

Weeks after induction

FIgure 5: Continued. 


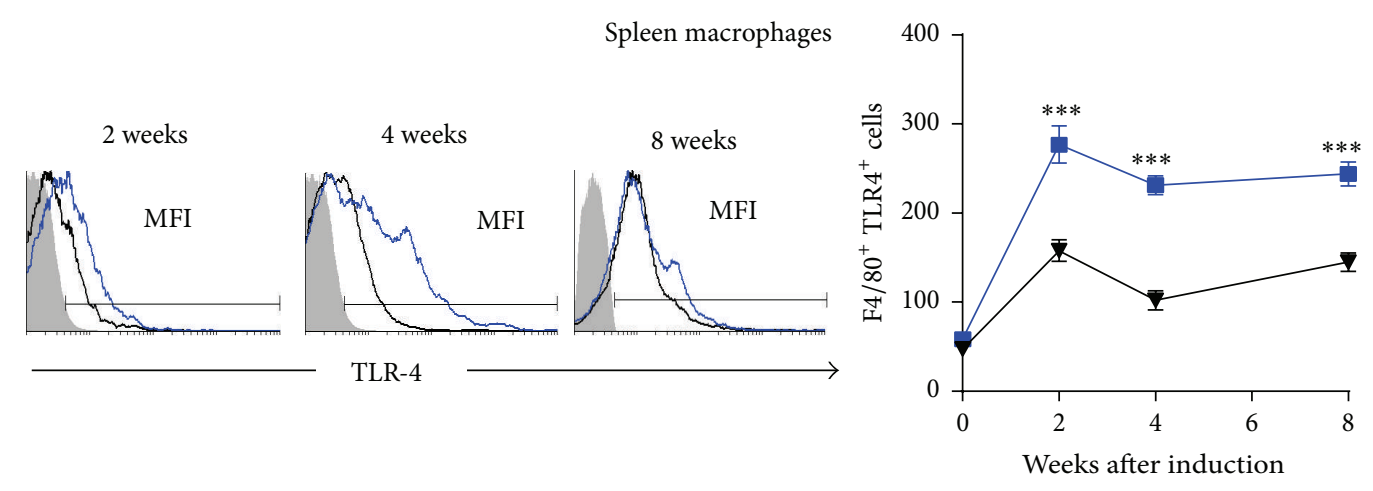

(e)

FIGURE 5: Mif promotes costimulatory molecule expression on spleen M $\varphi$. The time course of costimulatory molecule: CD80 (a), CD86 (b), MHC-II (c), TLR-2 (d), and TLR-4 (e) expression on spleen F4/80 ${ }^{+} \mathrm{M} \varphi . \mathrm{M} \varphi$ from spleen of Wt and Mif-/- mice were harvested at 0, 2, 4, and 8 weeks after STZ administration and $1 \times 10^{7}$ cells $/ \mathrm{mL}$ were processed by flow cytometric analysis as indicated in Section 2 . Analyses of expression are shown in the right panels: WtSTZ ( $\mathbf{})$; Mif-/-STZ $(\boldsymbol{\nabla})$. And representative histograms of expression based on fluorescence are shown in the left panels; isotype controls are indicated in gray shadow, the black line represents expression by Mif-/-STZ cells, and the blue line shows expression by WtSTZ cells. The data are presented as the mean fluorescence intensities (MFI) from one representative experiment. Each experiment was repeated three times $(n=3)$ and individually analyzed. ${ }^{*} p<0.05,{ }^{* *} p<0.01$, or ${ }^{* * *} p<0.001$, GraphPad Prism software 6.

Studies in NOD mice or mice treated with multiple low doses of STZ (despite the pathogenic differences between these models) have shown that pancreatic $\beta$ cell destruction results from the toxic effect of free radicals $\left(\mathrm{O}_{2}{ }^{-}, \mathrm{H}_{2} \mathrm{O}_{2}\right.$, and nitric oxide) and inflammatory cytokines released by activated $\mathrm{M} \varphi$ and $\mathrm{T}$ cells $[15,41,52]$. Therefore, both models have been widely used to dissect the role of Mif in the pathogenesis of T1DM using anti-Mif monoclonal antibody treatment or using Mif-/- mice. In all cases, the lack of Mif resulted in diminished manifestation of the disease, decreased glucose blood levels, and reduced production inflammatory cytokines associated with the development of T1DM, including TNF- $\alpha$, IL-1 $\beta$, IFN- $\gamma$, IL-12, and IL-23 [21, $22,24]$. Our study validates and extends these findings by demonstrating an important role for Mif in promoting costimulatory molecule expression in $\mathrm{M} \varphi$ and DC during T1DM development. We further demonstrate that, in addition to regulating $\mathrm{M} \varphi$ and $\mathrm{DC}$ activation in T1DM, M $\varphi$ isolated from T1DM Mif-/- mice exhibit reduced T cell activation.

Here, we observed that Wt mice treated with STZ exhibited high blood glucose levels greater than $400 \mathrm{mg} / \mathrm{dL}$ but Mif-/-STZ mice developed lower glucose levels of approximately $200 \mathrm{mg} / \mathrm{dL}$, in association with lower serum levels of proinflammatory cytokines. After reconstituting Mif using exogenous rMif, Mif-/-STZ showed blood glucose levels and IL-6 and IL-12 levels similar to those in WtSTZ from 2 to 6 weeks after STZ treatment. Interestingly, TNF- $\alpha$ serum levels from Mif-/-STZ+rMif were higher than those of WtSTZ at all time points analyzed. The reduction levels of blood glucose, IL-6, and IL-12 observed in Mif-/-STZ mice, on week 8 , probably were because the animals did not receive $\mathrm{rMif}$ injections on week 8 , as mentioned in Section 2, so the residual effect of rMif from week 1 to week 7 was insufficient to induce IL- 6 and IL-12 levels at 8 week similar to that observed in the WtSTZ mice in this point, at least for these two cytokines. These observations confirm that Mif exogenous acts as a powerful inducer of IL-6 and IL-12, but only if it is present in steady high concentration.

In addition, we found that Mif-/-STZ did not produce detectable levels of islet autoantibodies, in contrast to WtSTZ, which produced high levels of islet autoantibodies. It is well known that the early presence of islet autoantibodies is decisive in the development of diabetes by NOD mice as well as humans $[46,47,53]$. Our results confirm that Mif is essential for the development of hyperglycemia and suggest a role for Mif not only in the innate immune response but also in the adaptive immune response in T1DM.

Recently, it has been reported that Mif is produced by pancreatic $\beta$-cells and that Mif is released by insulin granules in an autocrine fashion $[54,55]$. The chemical destruction of $\beta$-pancreatic islets by STZ in Wt mice damaged $\beta$-pancreatic islets; this condition could reduce one major source of Mif in this experimental T1DM model. However, we did not observe a reduction in Mif levels in this model; in contrast, Wt mice produced high serum levels of Mif after STZ administration. In line with this finding, it is known that the pancreatic islets remaining after treatment with STZ produce high levels of Mif [21] and that an elevation of Mif secretion precedes pancreatic islet death induced by IFN- $\gamma$, TNF- $\alpha$, and IL- $1 \beta$ [24]. This evidence establishes that STZ did not influence Mif production/release by pancreatic islets or other cellular sources, such as T cells, DC, and $\mathrm{M} \varphi$ infiltrating the pancreas.

The loss of insulin production in T1DM is related to pancreatic $\beta$-cell destruction due to insulitis [56]. We observed that WtSTZ developed high serum levels of Mif and low insulin levels compared to Mif-/-STZ, which expressed insulin levels comparable to those in healthy mice. The histological analysis of pancreatic islets showed that WtSTZ displayed $100 \%$ insulitis, compared to the $33 \%$ insulitis observed in Mif-/-STZ mice. These observations confirm 
Journal of Diabetes Research

11

Spleen dendritic cells

2 weeks

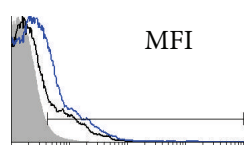

4 weeks

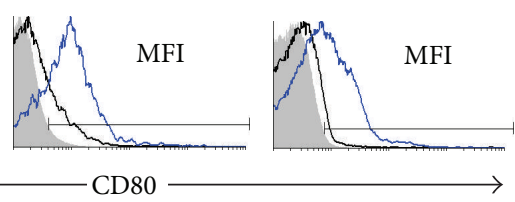

(a)

Spleen dendritic cells

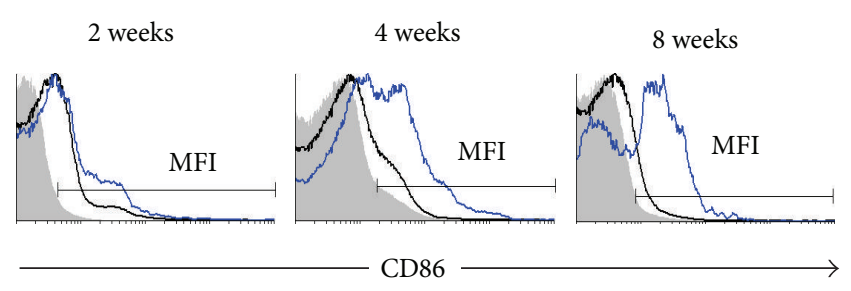

(b)

Spleen dendritic cells

2 weeks

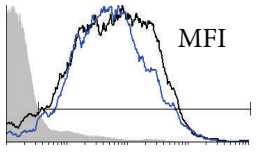

8 weeks

4 weeks

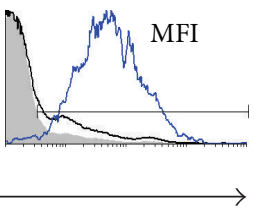

MHC-II

(c)

Spleen dendritic cells

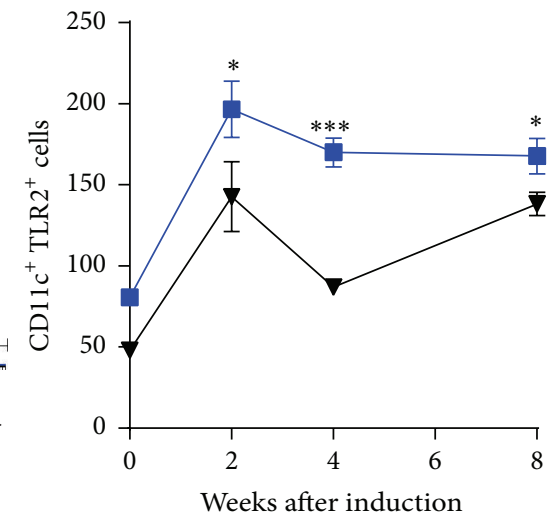

(d)

Figure 6: Continued. 


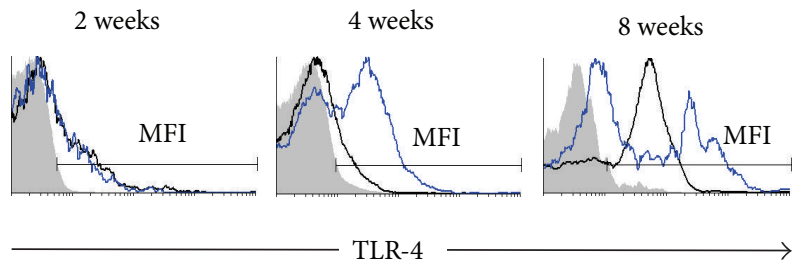

(e)

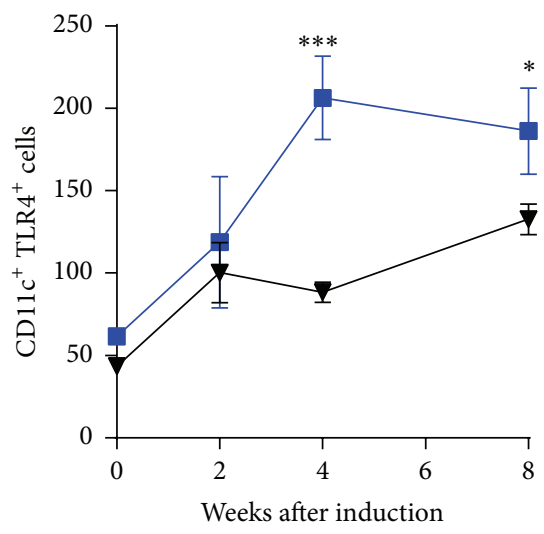

FIGURE 6: Mif promotes costimulatory molecules expression on spleen DC. The time course of costimulatory molecule: CD80 (a), CD86 (b), MHC-II (c), TLR-2 (d), and TLR-4 (e) expression on spleen CD11c ${ }^{+}$DC. DC from spleen of Wt and Mif-/- mice were harvested at 0, 2, 4, and 8 weeks after STZ administration and $1 \times 10^{7}$ cells $/ \mathrm{mL}$ were processed by flow cytometric analysis as indicated in Section 2 . Analyses of expression are shown in the right panels: WtSTZ $(\boldsymbol{\square}) ; \mathrm{Mif}-/-\mathrm{STZ}(\boldsymbol{\nabla})$. And representative histograms of expression based on fluorescence are shown in the left panels. Isotype controls are indicated in gray shadow, the black line represents expression by Mif-/-STZ cells, and the blue line shows expression by WtSTZ cells. The data are presented as the mean fluorescence intensities (MFI) from one representative experiment. Each experiment was repeated three times $(n=3)$ and individually analyzed. ${ }^{*} p<0.05,{ }^{* *} p<0.01$, or ${ }^{* * *} p<0.001$, GraphPad Prism software 6.

Pancreatic macrophages

2 weeks

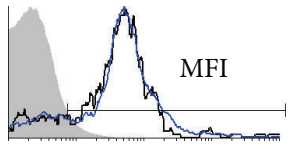

CD80
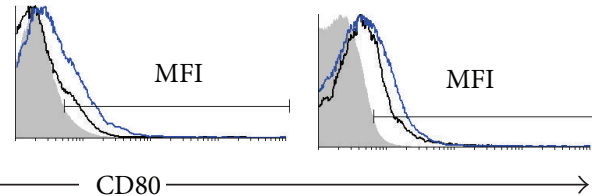

(a)

Pancreatic macrophages

2 weeks

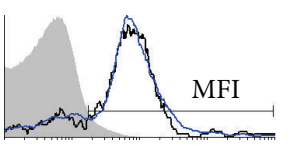

4 weeks

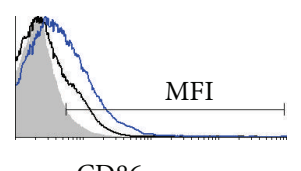

CD86
8 weeks

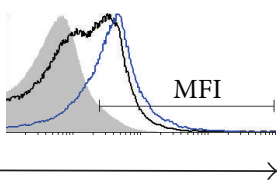

(b)
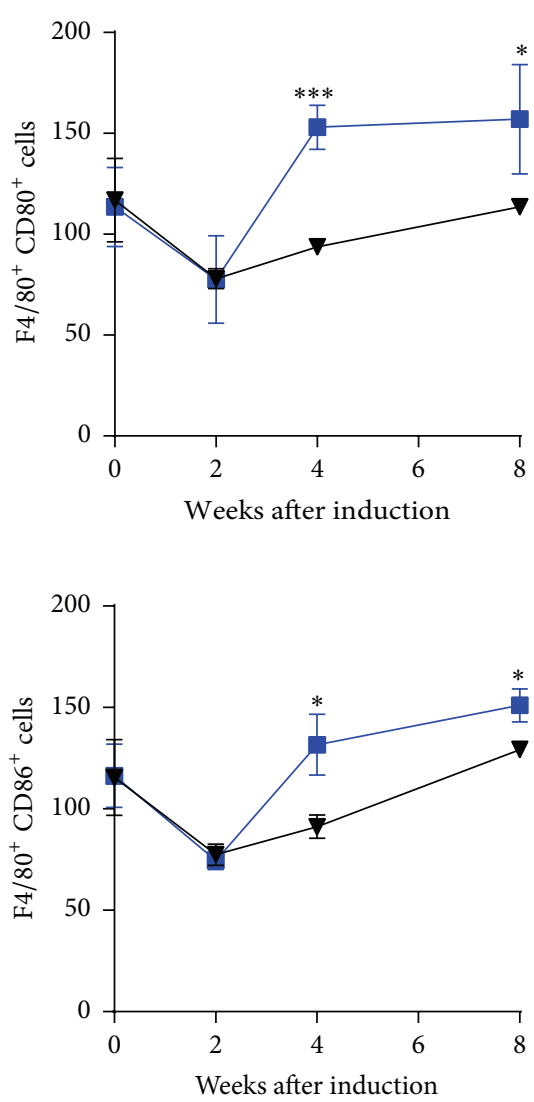

FIgURE 7: Continued. 


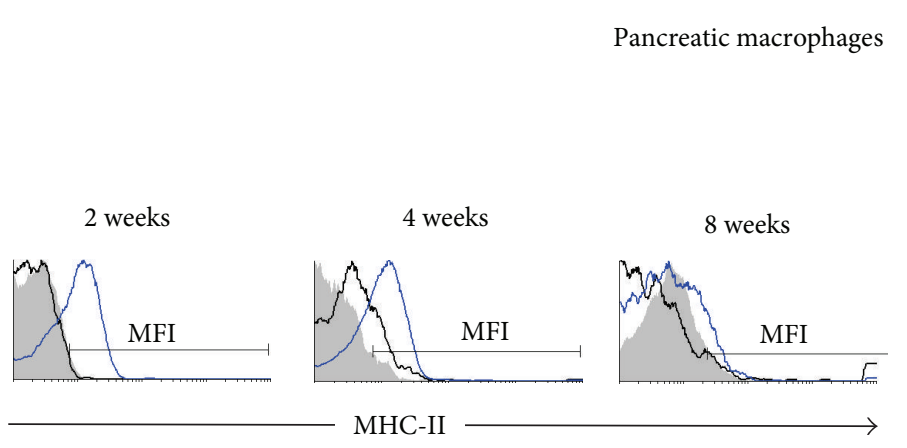

(c)

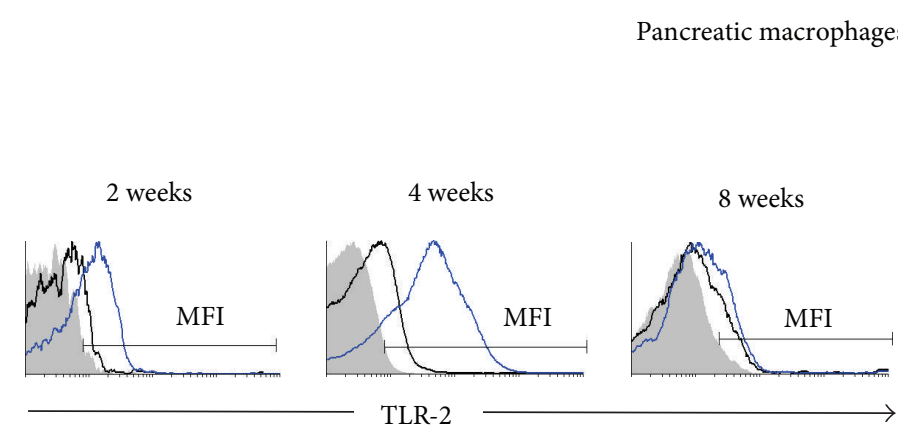

(d)

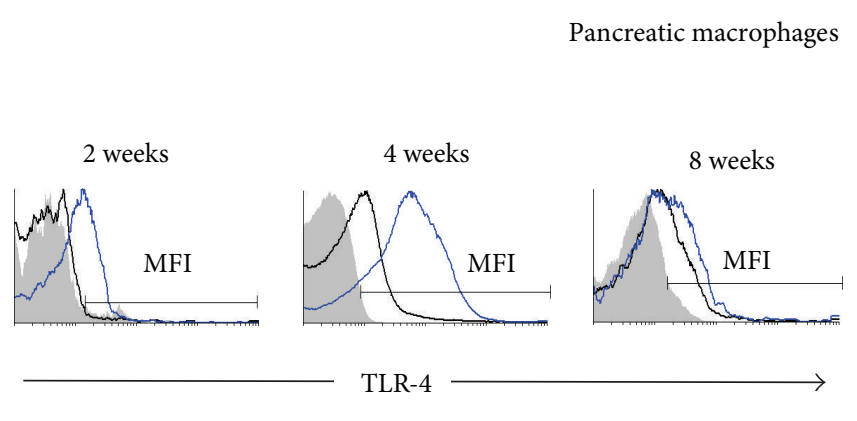

(e)
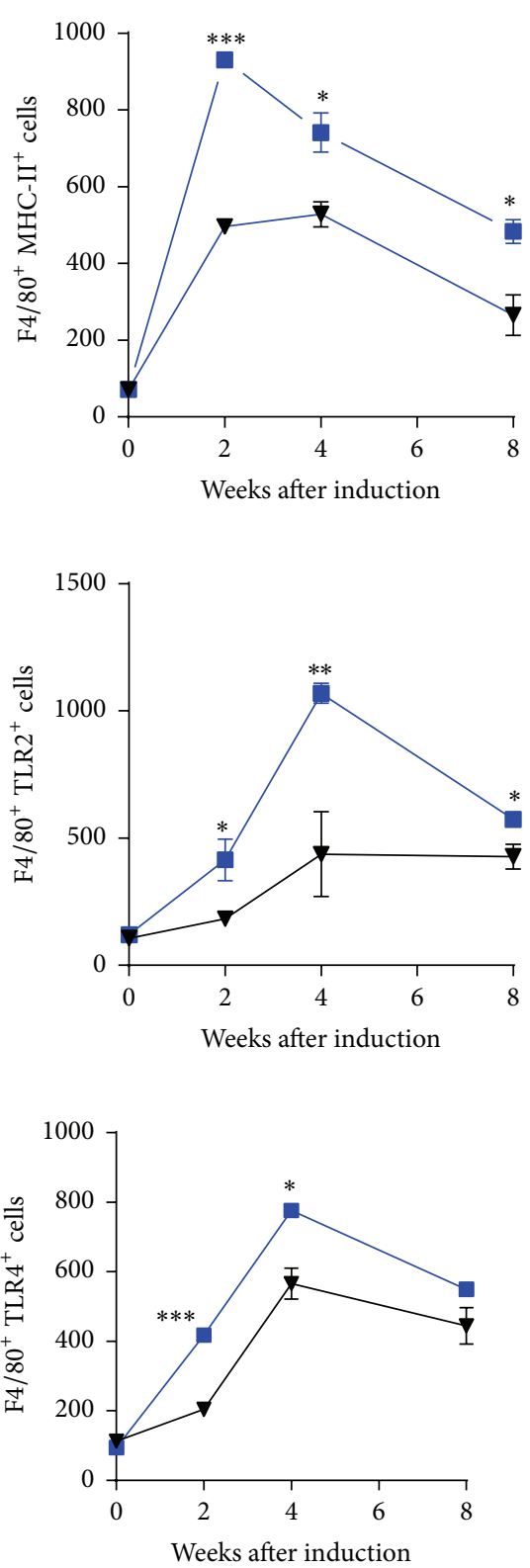

FIGURE 7: Mif promotes costimulatory molecule expression on pancreatic $\mathrm{M} \varphi$. The time course of costimulatory molecule: CD80 (a), CD86 (b), MHC-II (c), TLR-2 (d), and TLR-4 (e) expression on pancreatic F4/80 ${ }^{+} \mathrm{M} \varphi$. M $\varphi$ from pancreas of Wt and Mif-/- mice were harvested at $0,2,4$, and 8 weeks after STZ administration and $1 \times 10^{7}$ cells $/ \mathrm{mL}$ were processed by flow cytometric analysis as indicated in Section 2 . Analyses of expression are shown in the right panels: WtSTZ ( $\mathbf{\square})$; Mif-I-STZ $(\boldsymbol{\nabla})$. And representative histograms of expression based on fluorescence are shown in the left panels. Isotype controls are indicated in gray shadow, the black line represents expression by Mif-/-STZ cells, and the blue line shows expression by WtSTZ cells. The data are presented as the mean fluorescence intensities (MFI) from one representative experiment. Each experiment was repeated three times $(n=3)$ and individually analyzed. ${ }^{*} p<0.05,{ }^{* *} p<0.01$, or ${ }^{* * *} p<0.001$, GraphPad Prism software 6.

that Mif deficiency resulted in pancreatic islet protection, probably by controlling the functional activity and modulating the secretory capacity of proinflammatory cytokines produced by $\mathrm{T}$ cells, $\mathrm{DC}$, and $\mathrm{M} \varphi$ that reach the pancreatic cells.

Mif has been recognized as a molecule that not only promotes proinflammatory cytokine production but also acts as a chemokine. For example, Mif plays a crucial role in leukocyte recruitment and arrest during atherosclerosis development [57]. Therefore, Mif could participate in the process of insulitis to promote the production of proinflammatory cytokines, but Mif could also promote leukocyte recruitment to pancreatic $\beta$-cells. For this reason, Mif-/-STZ exhibited reduced insulitis. 
Pancreatic dendritic cells

2 weeks

4 weeks
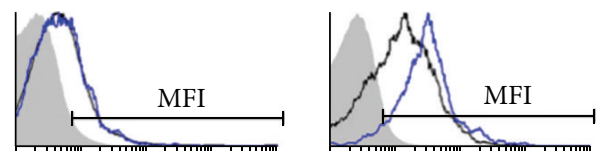

CD80

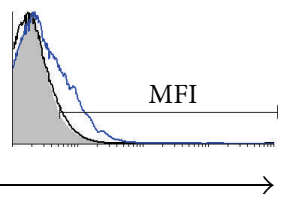

(a)
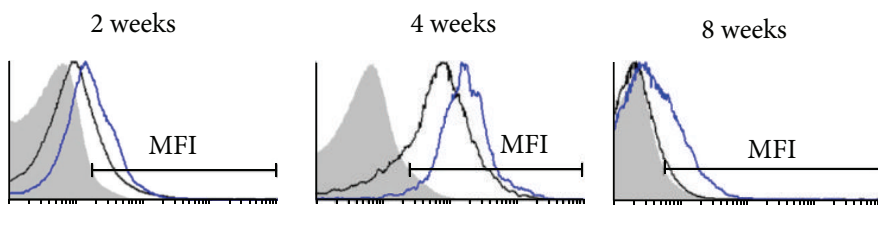

(b)
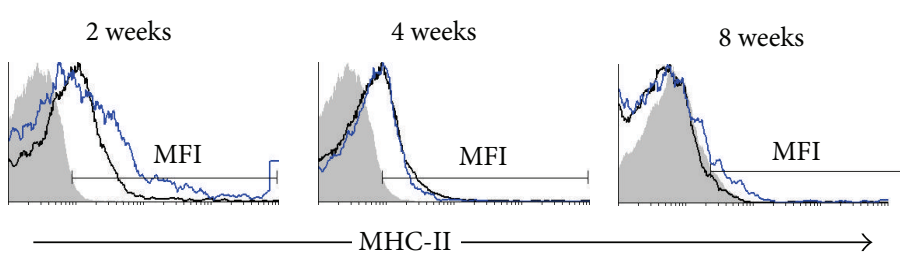

(c)

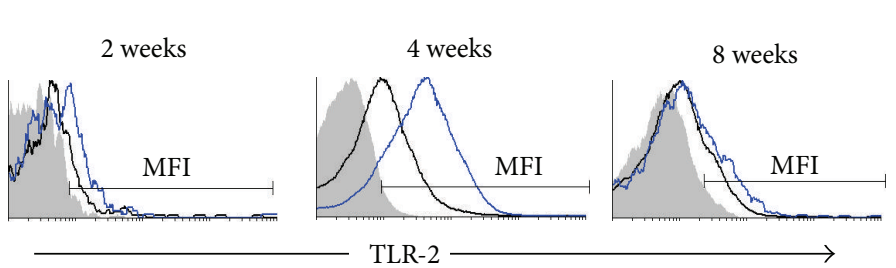

(d)
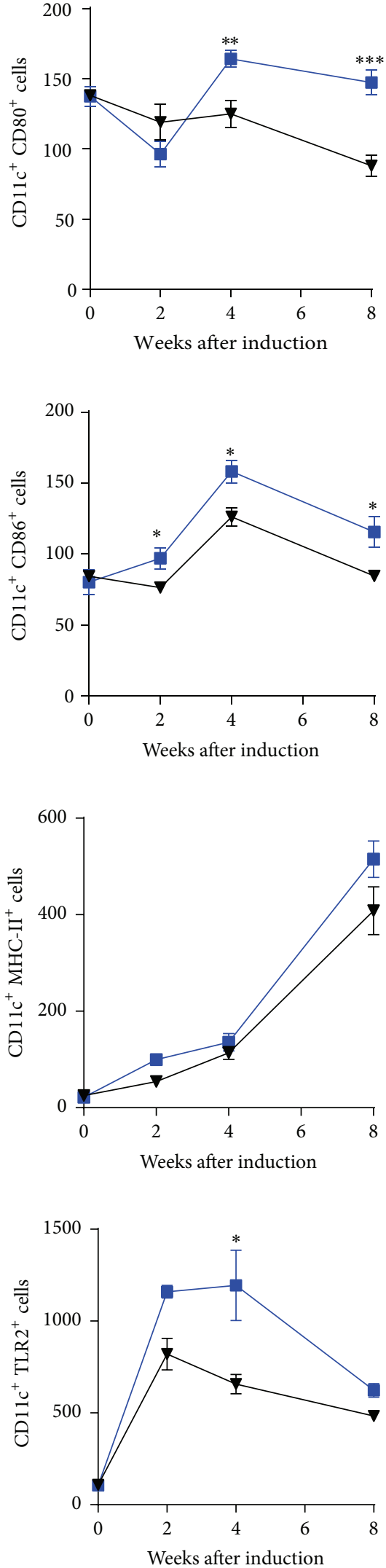

Figure 8: Continued. 

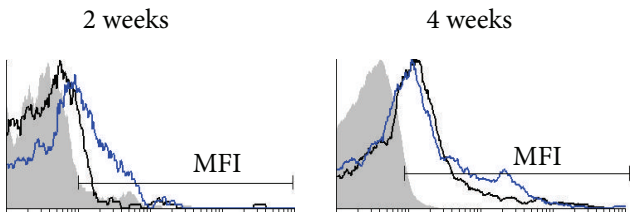

TLR-4
8 weeks

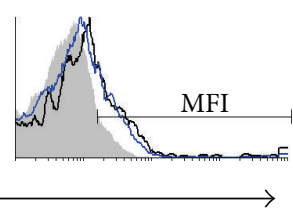

(e)

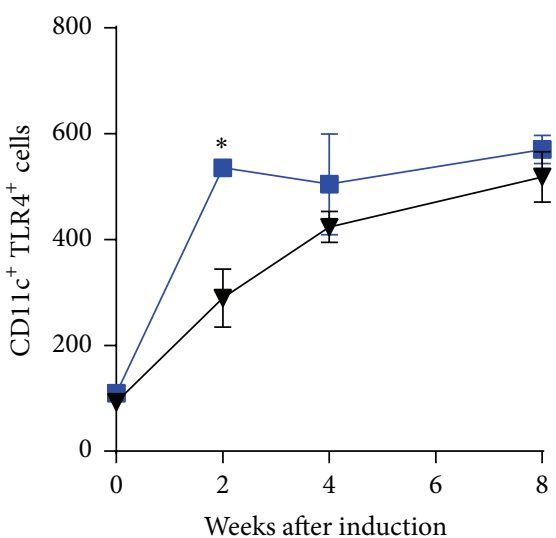

Weeks after induction

Figure 8: Mif promotes costimulatory molecules expression on pancreatic DC. The time course of costimulatory molecule: CD80 (a), CD86 (b), MHC-II (c), TLR-2 (d), and TLR-4 (e) expression on pancreatic CD11c DC. DC from pancreas of Wt and Mif-/- mice were harvested at 0, 2,4 , and 8 weeks after STZ administration and $1 \times 10^{7}$ cells $/ \mathrm{mL}$ were processed by flow cytometric analysis as indicated in Section 2 . Analyses of expression are shown in the right panels: WtSTZ $(\boldsymbol{\square})$; Mif-/-STZ $(\boldsymbol{\nabla})$. And representative histograms of expression based on fluorescence are shown in the left panels. Isotype controls are indicated in gray shadow, the black line represents expression by Mif-/-STZ cells, and the blue line shows expression by WtSTZ cells. The data are presented as the mean fluorescence intensities (MFI) from one representative experiment. Each experiment was repeated three times $(n=3)$ and individually analyzed. ${ }^{*} p<0.05,{ }^{* *} p<0.01$, or ${ }^{* * *} p<0.001$, GraphPad Prism software 6.

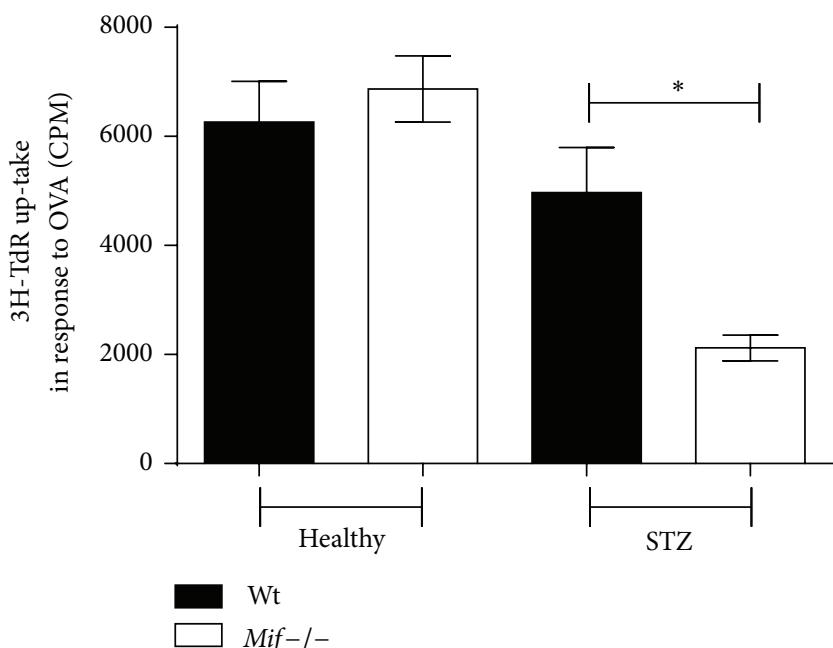

(a)

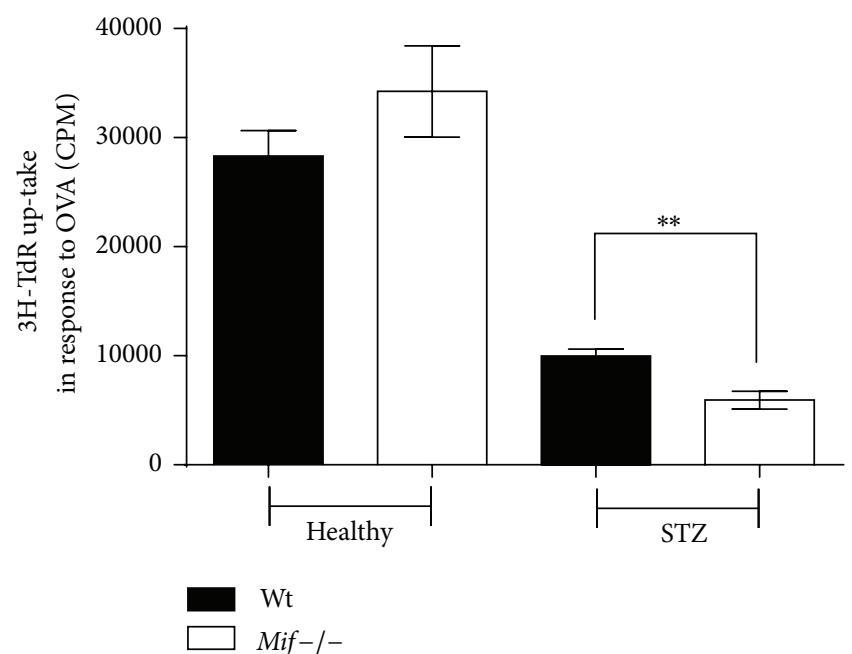

(b)

Figure 9: Macrophages and monocytes from Mif-/- mice have impaired ability to induce lymphocyte proliferation. At 8 weeks after STZ treatment, Wt $(\square)$ or Mif-/- ( $\square) \mathrm{M} \varphi\left(\mathrm{F} 4 / 80^{+}\right)$and monocytes $\left(\mathrm{CD}_{11 \mathrm{~b}}{ }^{+}\right)$primed with $10 \mu \mathrm{g} / \mathrm{mL}$ OVA were cocultured with OVA-transgenic T cells for 5 days. Subsequently, [3H]-thymidine was added for $18 \mathrm{~h}$, and [3H]-thymidine incorporation was measured. The values are presented as means \pm SEM counts per minute $(\mathrm{CPM})$ from triplicate wells of three independent experiments $(n=8) .{ }^{*} p<0.05$ or ${ }^{* *} p<0.01$. GraphPad Prism software 6, GraphPad Prism software 6.

Antigen-presenting cells, $\mathrm{M} \varphi$ and DC, are key mediators of the development of T1DM [4]. Moreover, it has been proposed that DC orchestrate the autoimmune response in T1DM via TLR-2 and TLR-4 [58]. Previous studies by us and others have shown that Mif induces the expression of costimulatory molecules on $\mathrm{M} \varphi$ and DC in some pathological infections [59-61]. Here, we identified the expression of costimulatory molecules and TLR-2 and TLR-4 on M $\varphi$ and $\mathrm{DC}$, as well as the ability of $\mathrm{M} \varphi$ to activate T lymphocytes.
Our results demonstrated that both $\mathrm{M} \varphi$ and $\mathrm{DC}$ from the spleen and pancreas of Mif-/-STZ mice expressed lower levels of CD80, CD86, MHC-II, TLR-2, and TLR-4 than those of WtSTZ. These results demonstrate a role of Mif in the activation of $\mathrm{M} \varphi$ and DC to promote costimulatory molecule expression, which might drive pancreas-specific T cell activation and effector Th1 subset differentiation, processes that have been associated with subsequent pancreatic injury in T1DM. 


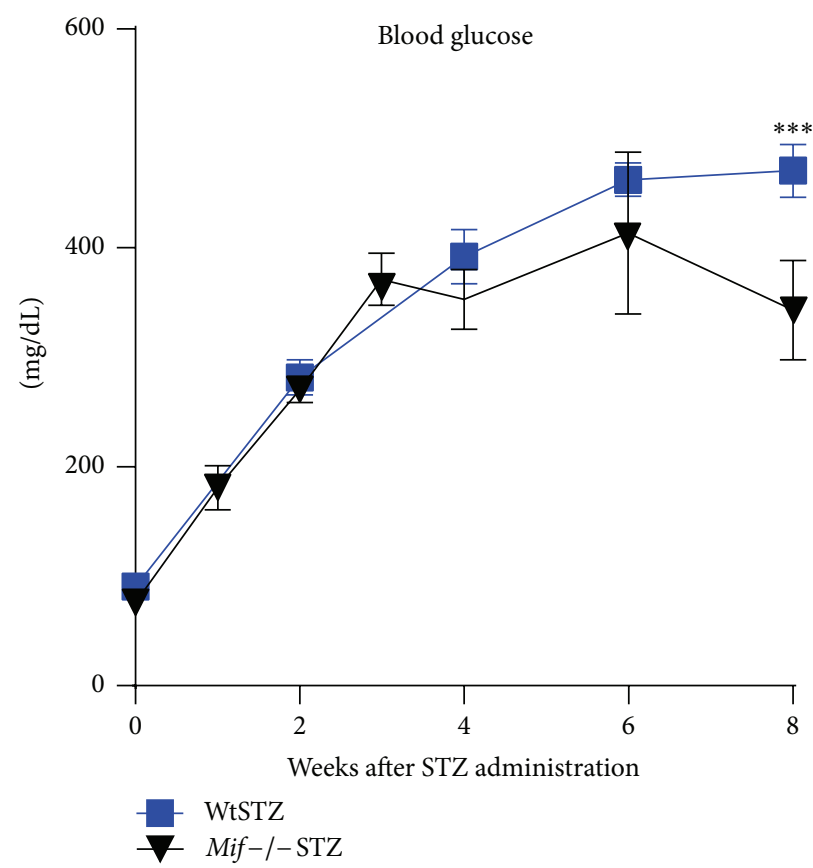

(a)

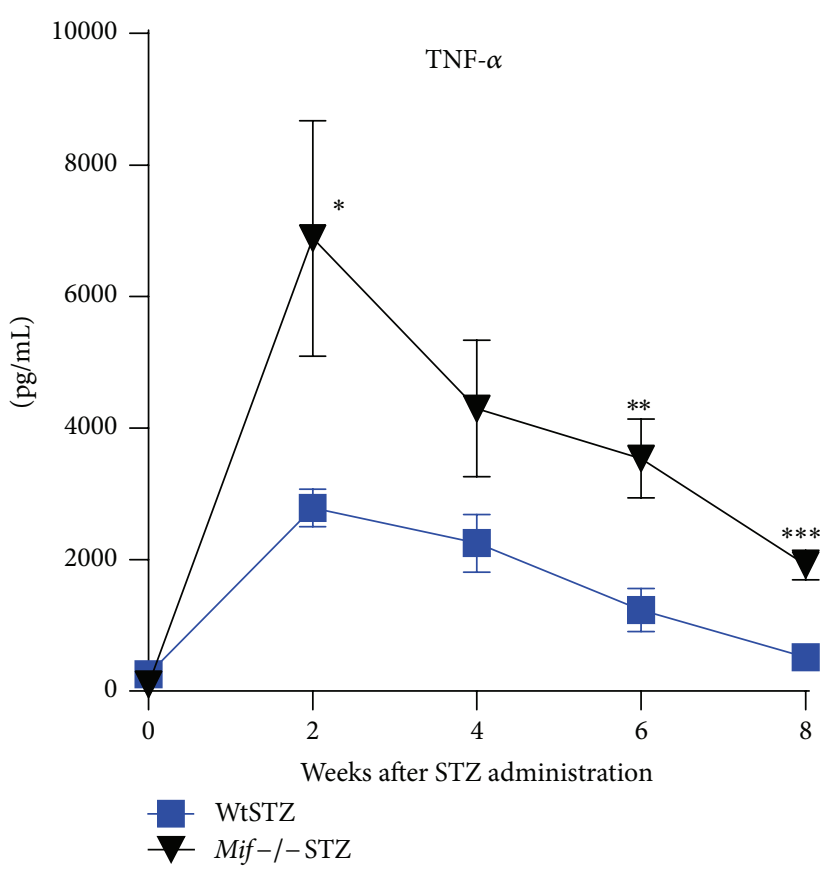

(c)

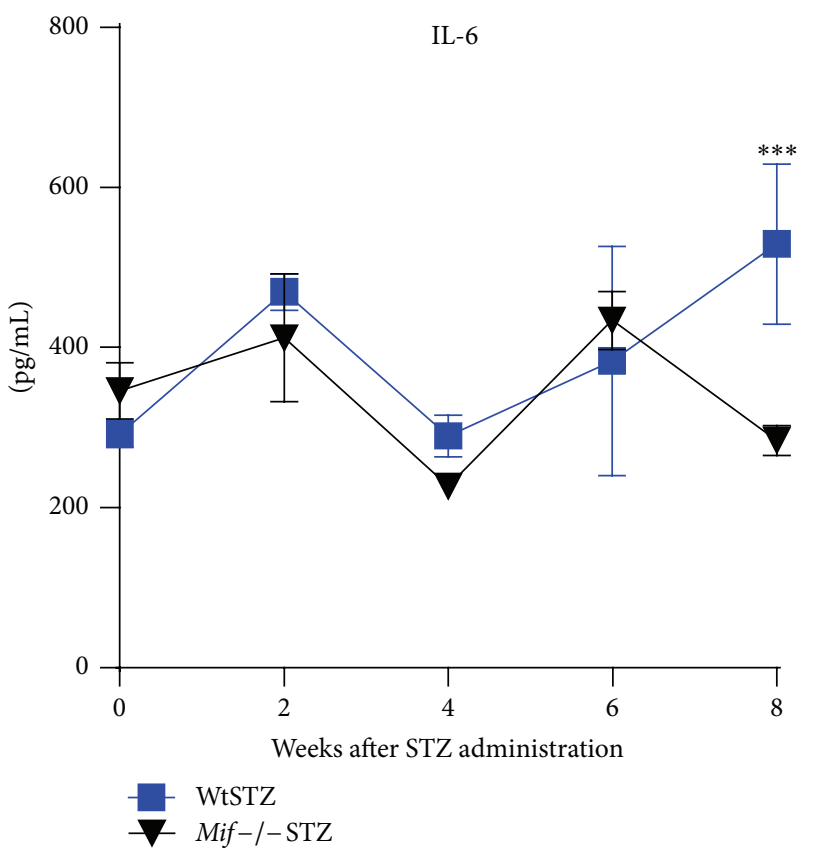

(b)

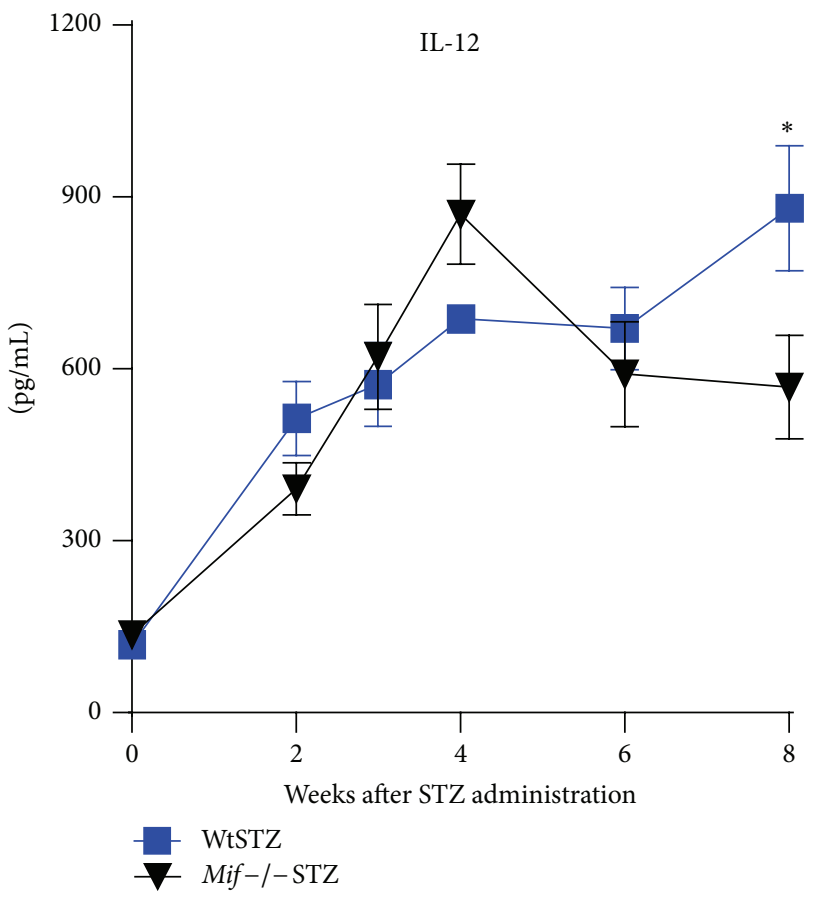

(d)

FIGURE 10: After Mif reconstitution, proinflammatory cytokine production in Mif-/- mice was increased.Mif reconstitution was initiated at the same time of STZ administration to Wt $(\boldsymbol{\nabla})$ or Mif-/- mice ( $\boldsymbol{\nabla})$ until 7 weeks after STZ treatment. The glucose levels (a) and the levels of the inflammatory cytokines IL-6 (b), TNF-a (c), and IL-12 (d) were measured. Control mice receiving vehicle injection did not display significant changes on cytokine production compared to week 0 (data do not shown). The values are expressed as the means \pm SEM of three independent experiments $(n=8) .{ }^{*} p<0.05,{ }^{* *} p<0.01$, or ${ }^{* * *} p<0.001$, GraphPad Prism software.

In line with the results described above, we observed that both $\mathrm{M} \varphi(\mathrm{F} 4 / 80)$ and monocytes $\left(\mathrm{CD}_{11 \mathrm{~b}}{ }^{+}\right)$from WtSTZ were more reactive and had greater ability to induce $T$ lymphocytespecific proliferation in response to OVA than those from
Mif-/-STZ mice. This finding is consistent with the evidence that proliferation of antigen-specific $\mathrm{T}$ cells from TCRtransgenic mice is highly dependent on CD28/CD86 costimulation. Disrupting this interaction dramatically reduces cell 
proliferation [62]. This conclusion agrees with the result that blocking CD86 prevents the development of diabetes in NOD mice [63]. Moreover, mutations in the MHC-II molecule lead to development of autoimmune diabetes [64].

By another hand, the differentiation state of $M \varphi$ is an important determinant for $\mathrm{T}$ cell response in T1DM. Two major populations have been defined, the classically activated (CA) $M \varphi$ secreting proinflammatory cytokines such as TNF- $\alpha$, IL- 6 , and IL- $1 \beta$ and reactive oxygen species; and alternatively activated (AA) $\mathrm{M} \varphi$ which secrete antiinflammatory factors including TGF- $\beta$ and IL-10. In T1DM it has been established that $\mathrm{CAM} \varphi$ trigger inflammatory responses which initiates insulitis and pancreatic $\beta$ cell death, whereas the $\operatorname{AAM} \varphi$ decreases hyperglycemia, insulitis, and inflammation in the pancreas [65].

As Mif is a regulator of many proinflammatory cytokines that are characteristic for the $\operatorname{CAM} \varphi$, Mif has been proposed as $\operatorname{CAM} \varphi$ macrophage-polarizing factor [66]. However, there are few and contrary experimental evidences about how Mif might participate in the polarization to $\operatorname{AAM} \varphi$ or $\operatorname{CAM} \varphi$. In a mouse model of nonalcoholic fatty liver disease $\mathrm{M} \varphi$ in liver from Mif-/- mice were skewed toward $\operatorname{AAM} \varphi$ [67]. By contrary, in the melanoma mouse model $\mathrm{M} \varphi$-derived Mif participates in $\operatorname{AAM} \varphi$ polarization [68]. Moreover, murine Mif and filarial nematode parasite (Brugia) Mif protein induced proinflammatory cytokines release. However, Mif also induce upregulation of IL-4 on bone marrow-derived mouse $\mathrm{M} \varphi$, which when treated in vitro with Mif and IL-4 induce AAM $\varphi$ [69]. Here, we show that $\mathrm{M} \varphi$ from Mif-/-STZ mice display reduced proinflammatory cytokine production and exhibit reduced ability to induce T lymphocyte proliferation in response to OVA. It is possible that Mif deficiency influences on $\mathrm{AAM} \varphi$ polarization in this model; however, more experiments are necessary to establish this.

\section{Conclusions}

We show for the first time a role of Mif in promoting costimulatory molecule expression in $\mathrm{M} \varphi$ and DC in T1DM. These results reveal Mif as a key regulator of proinflammatory function and $\mathrm{M} \varphi$ and DC activation in T1DM. Although more specific experiments are required, there is no doubt that Mif represents a potential target for anti-Mif therapy, which might attenuate the autoimmune process in T1DM.

\section{Competing Interests}

The authors have no conflicting financial or commercial interests.

\section{Acknowledgments}

This study is part of the work of Yuriko Itzel Sánchez-Zamora to obtain a Ph.D. degree in the Programa de Doctorado en Ciencias Biomédicas, Universidad Nacional Autónoma de México (UNAM), and she received a Fellowship (no. 349680) from CONACYT. The authors thank Dr. J. de D. RuizRosado and Nikhil Reddy for critically reading this paper (Nationwide Children's Hospital, OSU, USA). This work was supported by Grant IN212215 from PAPIIT (DGAPA, UNAM, México) and by Grant 152224 from CONACYT to Miriam Rodriguez-Sosa.

\section{References}

[1] F. S. Malik and C. E. Taplin, "Insulin therapy in children and adolescents with type 1 diabetes," Pediatric Drugs, vol. 16, no. 2, pp. 141-150, 2014.

[2] American Diabetes Association, "Diagnosis and classification of diabetes mellitus," Diabetes Care, vol. 37, supplement 1, pp. S81-S90, 2013.

[3] S. Canivell and R. Gomis, "Diagnosis and classification of autoimmune diabetes mellitus," Autoimmunity Reviews, vol. 13, no. 4-5, pp. 403-407, 2014.

[4] A. Willcox, S. J. Richardson, A. J. Bone, A. K. Foulis, and N. G. Morgan, "Analysis of islet inflammation in human type 1 diabetes," Clinical \& Experimental Immunology, vol. 155, no. 2, pp. 173-181, 2009.

[5] M. E. Craig, S. Nair, H. Stein, and W. D. Rawlinson, "Viruses and type 1 diabetes: a new look at an old story," Pediatric Diabetes, vol. 14, no. 3, pp. 149-158, 2013.

[6] A. Salvatoni, A. Baj, G. Bianchi, G. Federico, M. Colombo, and A. Toniolo, "Intrafamilial spread of enterovirus infections at the clinical onset of type 1 diabetes," Pediatric Diabetes, vol. 14, no. 6, pp. 407-416, 2013.

[7] G. Afonso and R. Mallone, "Infectious triggers in type 1 diabetes: is there a case for epitope mimicry?" Diabetes, Obesity and Metabolism, vol. 15, supplement 3, pp. 82-88, 2013.

[8] Å. Lernmark and C.-D. Agardh, "Immunomodulation with human recombinant autoantigens," Trends in Immunology, vol. 26, no. 11, pp. 608-612, 2005.

[9] M. Pearl-Yafe, A. Kaminitz, E. S. Yolcu, I. Yaniv, J. Stein, and N. Askenasy, "Pancreatic islets under attack: cellular and molecular effectors," Current Pharmaceutical Design, vol. 13, no. 7, pp. 749760, 2007.

[10] Y. Dogan, S. Akarsu, B. Ustundag, E. Yilmaz, and M. K. Gurgoze, "Serum IL-1 $\beta$, IL-2, and IL-6 in insulin-dependent diabetic children," Mediators of Inflammation, vol. 2006, Article ID 59206, 6 pages, 2006.

[11] B. Baumann, H. H. Salem, and B. O. Boehm, "Anti-inflammatory therapy in type 1 diabetes," Current Diabetes Reports, vol. 12, no. 5, pp. 499-509, 2012.

[12] C. Y. Westwell-Roper, J. A. Ehses, and C. B. Verchere, "Resident macrophages mediate islet amyloid polypeptide-induced islet IL- $1 \beta$ production and $\beta$-cell dysfunction," Diabetes, vol. 63 , no. 5, pp. 1698-1711, 2014.

[13] T. Mandrup-Poulsen, L. Pickersgill, and M. Y. Donath, "Blockade of interleukin 1 in type 1 diabetes mellitus," Nature Reviews Endocrinology, vol. 6, no. 3, pp. 158-166, 2010.

[14] T. Mandrup-Poulsen, "Interleukin-1 antagonists and other cytokine blockade strategies for type 1 diabetes," Review of Diabetic Studies, vol. 9, no. 4, pp. 338-347, 2012.

[15] X.-L. Zou, Z.-Y. Zhao, Y.-Y. Wan, Z.-Q. Su, and M. Xiang, "Diabetogenic T cells induce autoimmune diabetes in BALB/c mice," Chinese Medical Sciences Journal, vol. 23, no. 2, pp. 88-94, 2008.

[16] J. Myśliwska, M. Smardzewski, N. Marek-Trzonkowska, M. Myśliwiec, and K. Raczyńska, "Expansion of $\mathrm{CD}_{14}{ }^{+} \mathrm{CD} 16^{+}$ monocytes producing TNF- $\alpha$ in complication-free diabetes type 1 juvenile onset patients," Cytokine, vol. 60, no. 1, pp. 309317, 2012. 
[17] M. Rachmiel, O. Bloch, A. A. Shaul et al., "Young patients with both type 1 diabetes mellitus and asthma have a unique IL-12 and IL-18 secretory pattern," Pediatric Diabetes, vol. 12, no. 7, pp. 596-603, 2011.

[18] A. E. Altinova, D. Engin, E. Akbay et al., "Association of polymorphisms in the IL-18 and IL-12 genes with susceptibility to type 1 diabetes in Turkish patients," Journal of Endocrinological Investigation, vol. 33, no. 7, pp. 451-454, 2010.

[19] P. Hanifi-Moghaddam, N. C. Schloot, S. Kappler, J. Seißler, and H. Kolb, "An association of autoantibody status and serum cytokine levels in type 1 diabetes," Diabetes, vol. 52, no. 5, pp. 1137-1142, 2003.

[20] J. Bojunga, K. Kusterer, M. Bacher, R. Kurek, K.-H. Usadel, and H. Renneberg, "Macrophage migration inhibitory factor and development of type-1 diabetes in non-obese diabetic mice," Cytokine, vol. 21, no. 4, pp. 179-186, 2003.

[21] I. Cvetkovic, Y. Al-Abed, D. Miljkovic et al., "Critical role of macrophage migration inhibitory factor activity in experimental autoimmune diabetes," Endocrinology, vol. 146, no. 7, pp. 2942-2951, 2005.

[22] S. Stosic-Grujicic, I. Stojanovic, D. Maksimovic-Ivanic et al., "Macrophage migration inhibitory factor (MIF) is necessary for progression of autoimmune diabetes mellitus," Journal of Cellular Physiology, vol. 215, no. 3, pp. 665-675, 2008.

[23] Y. I. Sánchez-Zamora and M. Rodriguez-Sosa, "The role of MIF in type 1 and type 2 diabetes mellitus," Journal of Diabetes Research, vol. 2014, Article ID 804519, 6 pages, 2014.

[24] I. Stojanovic, T. Saksida, I. Nikolic, F. Nicoletti, and S. StosicGrujicic, "Macrophage migration inhibitory factor deficiency protects pancreatic islets from cytokine-induced apoptosis in vitro," Clinical and Experimental Immunology, vol. 169, no. 2, pp. 156-163, 2012.

[25] T. Roger, M. P. Glauser, and T. Calandra, "Macrophage migration inhibitory factor (MIF) modulates innate immune responses induced by endotoxin and Gram-negative bacteria," Journal of Endotoxin Research, vol. 7, no. 6, pp. 456-460, 2001.

[26] S. N. Babu, G. Chetal, and S. Kumar, "Macrophage migration inhibitory factor: a potential marker for cancer diagnosis and therapy," Asian Pacific Journal of Cancer Prevention, vol. 13, no. 5, pp. 1737-1744, 2012.

[27] J. Nishihira, "Molecular function of macrophage migration inhibitory factor and a novel therapy for inflammatory bowel disease," Annals of the New York Academy of Sciences, vol. 1271, no. 1, pp. 53-57, 2012.

[28] J. Nishihira and K. Mitsuyama, "Overview of the role of macrophage migration inhibitory factor (MIF) in inflammatory bowel disease," Current Pharmaceutical Design, vol. 15, no. 18, pp. 2104-2109, 2009.

[29] L. L. Santos and E. F. Morand, "Macrophage migration inhibitory factor: a key cytokine in RA, SLE and atherosclerosis," Clinica Chimica Acta, vol. 399, no. 1-2, pp. 1-7, 2009.

[30] Z. Szekanecz, T. Besenyei, Á. Szentpétery, and A. E. Koch, "Angiogenesis and vasculogenesis in rheumatoid arthritis," Current Opinion in Rheumatology, vol. 22, no. 3, pp. 299-306, 2010.

[31] O. M. Finucane, C. M. Reynolds, F. C. McGillicuddy, and H. $\mathrm{M}$. Roche, "Insights into the role of macrophage migration inhibitory factor in obesity and insulin resistance," Proceedings of the Nutrition Society, vol. 71, no. 4, pp. 622-633, 2012.

[32] R. Kleemann and R. Bucala, "Macrophage migration inhibitory factor: critical role in obesity, insulin resistance, and associated comorbidities," Mediators of Inflammation, vol. 2010, Article ID 610479, 7 pages, 2010.

[33] C. Toso, J. A. Emamaullee, S. Merani, and A. M. J. Shapiro, "The role of macrophage migration inhibitory factor on glucose metabolism and diabetes," Diabetologia, vol. 51, no. 11, pp. 19371946,2008

[34] J. Nishihira, "Novel pathophysiological aspects of macrophage migration inhibitory factor (review)," International Journal of Molecular Medicine, vol. 2, no. 1, pp. 17-28, 1998.

[35] Y. Sanchez-Zamora, L. I. Terrazas, A. Vilches-Flores et al., "Macrophage migration inhibitory factor is a therapeutic target in treatment of non-insulin-dependent diabetes mellitus," The FASEB Journal, vol. 24, no. 7, pp. 2583-2590, 2010.

[36] G. Grieb, M. Merk, J. Bernhagen, and R. Bucala, "Macrophage Migration Inhibitory Factor (MIF): a promising biomarker," Drug News and Perspectives, vol. 23, no. 4, pp. 257-264, 2010.

[37] M. Leech, C. Metz, P. Hall et al., "Macrophage migration inhibitory factor in rheumatoid arthritis: evidence of proinflammatory function and regulation by glucocorticoids," Arthritis and Rheumatism, vol. 42, no. 8, pp. 1601-1608, 1999.

[38] S. Onodera, H. Tanji, K. Suzuki et al., "High expression of macrophage migration inhibitory factor in the synovial tissues of rheumatoid joints," Cytokine, vol. 11, no. 2, pp. 163-167, 1999.

[39] J. Yun, C.-T. Xu, and B.-R. Pan, "Epidemiology and gene markers of ulcerative colitis in the Chinese," World Journal of Gastroenterology, vol. 15, no. 7, pp. 788-803, 2009.

[40] P. W. Laird, A. Zijderveld, K. Linders, M. A. Rudnicki, R. Jaenisch, and A. Berns, "Simplified mammalian DNA isolation procedure," Nucleic Acids Research, vol. 19, no. 15, article 4293, 1991.

[41] M. L. Lukic, S. Stošic-Grujicic, and A. Shahin, "Effector mechanisms in low-dose streptozotocin-induced diabetes," Developmental Immunology, vol. 6, no. 1-2, pp. 119-128, 1998.

[42] M. A. K. Markwell, S. M. Haas, L. L. Bieber, and N. E. Tolbert, "A modification of the Lowry procedure to simplify protein determination in membrane and lipoprotein samples," Analytical Biochemistry, vol. 87, no. 1, pp. 206-210, 1978.

[43] E. E. Hillhouse, R. Collin, G. Chabot-Roy et al., "Nearby construction impedes the progression to overt autoimmune diabetes in NOD mice," Journal of Diabetes Research, vol. 2013, Article ID 620313, 7 pages, 2013.

[44] D. S. Li, Y. Yuan, H. Tu, Q. Liang, and L. Dai, "A protocol for islet isolation from mouse pancreas," Nature Protocols, vol. 4, no. 11, pp. 1649-1652, 2009.

[45] A. M. Ortiz-Flores, Y. Ledesma-Soto, E. A. Calleja, M. Rodríguez-Sosa, I. Juárez, and L. I. Terrazas, "Taenia crassiceps infection does not influence the development of experimental rheumatoid arthritis," BioMed Research International, vol. 2013, Article ID 316980, 9 pages, 2013.

[46] L. Yu, D. T. Robles, N. Abiru et al., "Early expression of antiinsulin autoantibodies of humans and the NOD mouse: evidence for early determination of subsequent diabetes," Proceedings of the National Academy of Sciences of the United States of America, vol. 97, no. 4, pp. 1701-1706, 2000.

[47] A. K. Steck, K. Johnson, K. J. Barriga et al., "Age of islet autoantibody appearance and mean levels of insulin, but not GAD or IA-2 autoantibodies, predict age of diagnosis of type 1 diabetes: diabetes autoimmunity study in the young," Diabetes Care, vol. 34, no. 6, pp. 1397-1399, 2011.

[48] S. Rex, S. Kraemer, G. Grieb et al., "The role of macrophage migration inhibitory factor in critical illness," Mini-Reviews in Medicinal Chemistry, vol. 14, no. 14, pp. 1116-1124, 2014. 
[49] J. D. D. Rosado and M. Rodriguez-Sosa, "Macrophage migration inhibitory factor (MIF): a key player in protozoan infections," International Journal of Biological Sciences, vol. 7, no. 9, pp. 1239-1256, 2011.

[50] K. Kim and H. Kim, "Macrophage migration inhibitory factor: a potential therapeutic target for rheumatoid arthritis," The Korean Journal of Internal Medicine, vol. 31, no. 4, pp. 634-642, 2016.

[51] C. Pfleger, N. C. Schloot, M. D. Brendel et al., "Circulating cytokines are associated with human islet graft function in type 1 diabetes," Clinical Immunology, vol. 138, no. 2, pp. 154-161, 2011.

[52] H. Kolb, "Mouse models of insulin dependent diabetes: lowdose streptozocin-induced diabetes and nonobese diabetic (NOD) mice," Diabetes/Metabolism Reviews, vol. 3, no. 3, pp. 751-778, 1987.

[53] A. K. Steck, K. Vehik, E. Bonifacio et al., "Predictors of progression from the appearance of islet autoantibodies to early childhood diabetes: the Environmental Determinants of Diabetes in the Young (TEDDY)," Diabetes Care, vol. 38, no. 5, pp. 808-813, 2015.

[54] G. Waeber, T. Calandra, R. Roduit et al., "Insulin secretion is regulated by the glucose-dependent production of islet $\beta$ cell macrophage migration inhibitory factor," Proceedings of the National Academy of Sciences of the United States of America, vol. 94, no. 9, pp. 4782-4787, 1997.

[55] G. Waeber, T. Calandra, C. Bonny, and R. Bucala, "A role for the endocrine and pro-inflammatory mediator MIF in the control of insulin secretion during stress," Diabetes/Metabolism Research and Reviews, vol. 15, no. 1, pp. 47-54, 1999.

[56] N. G. Morgan, P. Leete, A. K. Foulis, and S. J. Richardson, "Islet inflammation in human type 1 diabetes mellitus," IUBMB Life, vol. 66, no. 11, pp. 723-734, 2014.

[57] E. P. C. van der Vorst, Y. Döring, and C. Weber, "Chemokines and their receptors in Atherosclerosis," Journal of Molecular Medicine, vol. 93, no. 9, pp. 963-971, 2015.

[58] D. L. Eizirik, M. L. Colli, and F. Ortis, "The role of inflammation in insulitis and $\beta$-cell loss in type 1 diabetes," Nature Reviews Endocrinology, vol. 5, no. 4, pp. 219-226, 2009.

[59] A. B. Stavitsky and J. Xianli, "In vitro and in vivo regulation by macrophage migration inhibitory factor (MIF) of expression of MHC-II, costimulatory, adhesion, receptor, and cytokine molecules," Cellular Immunology, vol. 217, no. 1-2, pp. 95-104, 2002.

[60] C. A. Terrazas, E. Huitron, A. Vazquez et al., "MIF synergizes with Trypanosoma cruzi antigens to promote efficient dendritic cell maturation and IL-12 production via p38 MAPK," International Journal of Biological Sciences, vol. 7, no. 9, pp. 1298-1310, 2011.

[61] J. de Dios Ruiz-Rosado, J. E. Olguín, I. Juárez-Avelar et al., "MIF promotes classical activation and conversion of inflammatory Ly6C ${ }^{\text {high }}$ monocytes into tipdcs during murine toxoplasmosis," Mediators of Inflammation, vol. 2016, Article ID 9101762, 18 pages, 2016.

[62] B. Salomon and J. A. Bluestone, "Complexities of CD28/B7: CTLA-4 costimulatory pathways in autoimmunity and transplantation," Annual Review of Immunology, vol. 19, pp. 225-252, 2001.

[63] D. J. Lenschow, S. C. Ho, H. Sattar et al., "Differential effects of anti-B7-1 and anti-B7-2 monoclonal antibody treatment on the development of diabetes in the nonobese diabetic mouse," Journal of Experimental Medicine, vol. 181, no. 3, pp. 1145-1155, 1995.
[64] J. J. Racine, M. Zhang, M. Wang, W. Morales, C. Shen, and D. Zeng, "MHC-mismatched mixed chimerism mediates thymic deletion of cross-reactive autoreactive $\mathrm{T}$ cells and prevents insulitis in nonobese diabetic mice," The Journal of Immunology, vol. 194, no. 1, pp. 407-417, 2015.

[65] A. Espinoza-Jiménez, A. N. Peón, and L. I. Terrazas, "Alternatively activated macrophages in types 1 and 2 diabetes," Mediators of Inflammation, vol. 2012, Article ID 815953, 10 pages, 2012.

[66] B.-S. Kim, N. Pallua, J. Bernhagen, and R. Bucala, "The macrophage migration inhibitory factor protein superfamily in obesity and wound repair," Experimental and Molecular Medicine, vol. 47, article e161, 2015.

[67] D. Heinrichs, M.-L. Berres, M. Coeuru et al., "Protective role of macrophage migration inhibitory factor in nonalcoholic steatohepatitis," The FASEB Journal, vol. 28, no. 12, pp. 51365147, 2014.

[68] K. Yaddanapudi, K. Putty, B. E. Rendon et al., "Control of tumor-associated macrophage alternative activation by macrophage migration inhibitory factor," The Journal of Immunology, vol. 190, no. 6, pp. 2984-2993, 2013.

[69] L. Prieto-Lafuente, W. F. Gregory, J. E. Allen, and R. M. Maizels, "MIF homologues from a filarial nematode parasite synergize with IL-4 to induce alternative activation of host macrophages," Journal of Leukocyte Biology, vol. 85, no. 5, pp. 844-854, 2009. 


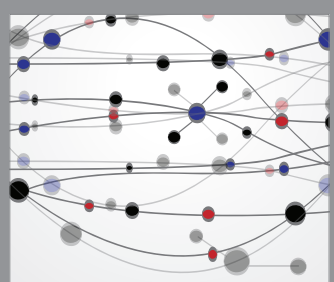

The Scientific World Journal
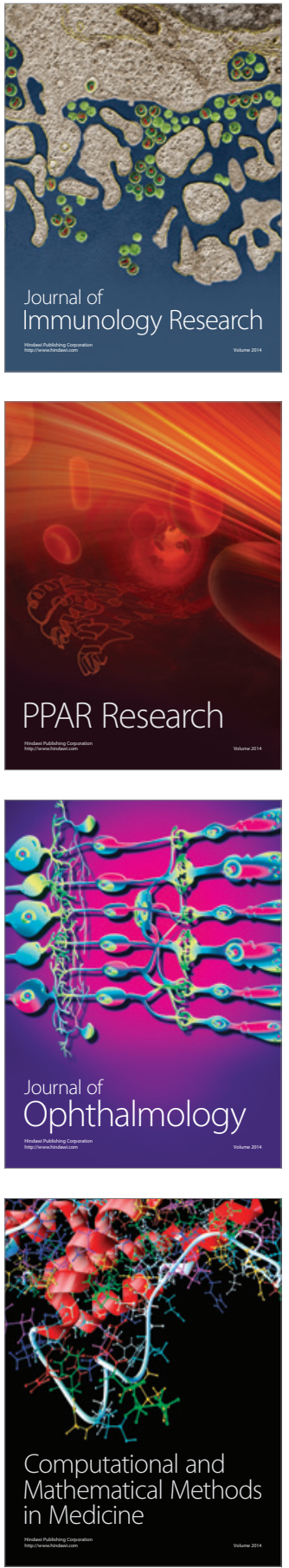

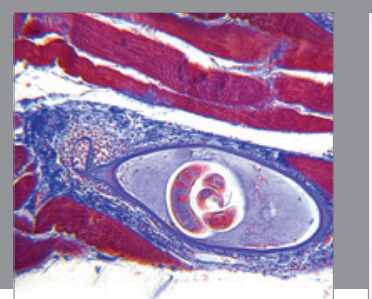

Gastroenterology Research and Practice

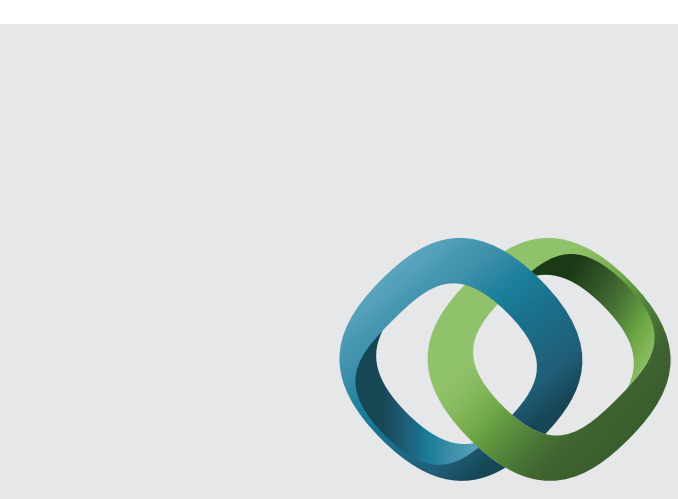

\section{Hindawi}

Submit your manuscripts at

http://www.hindawi.com
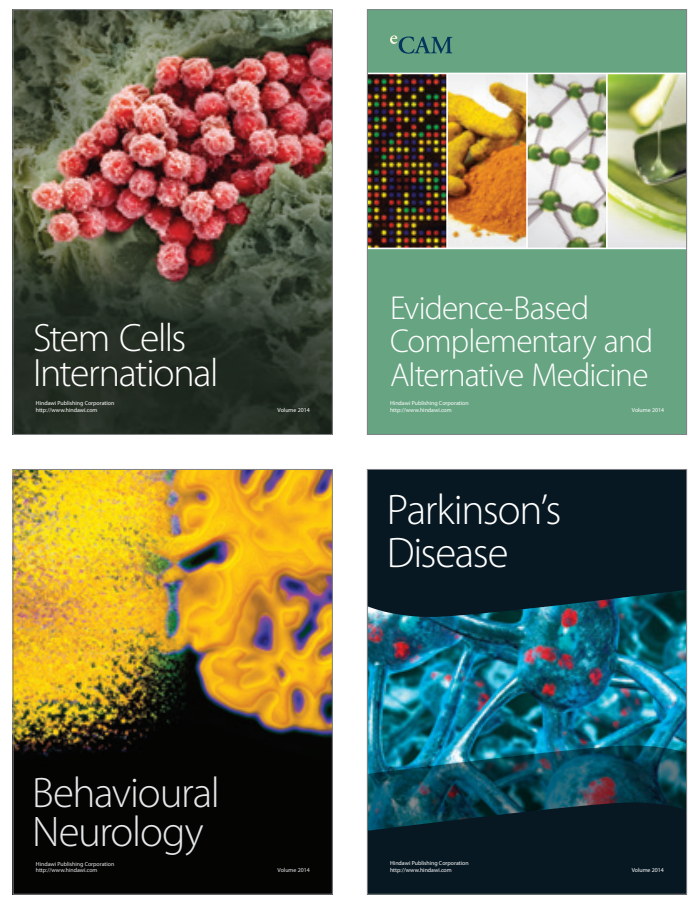
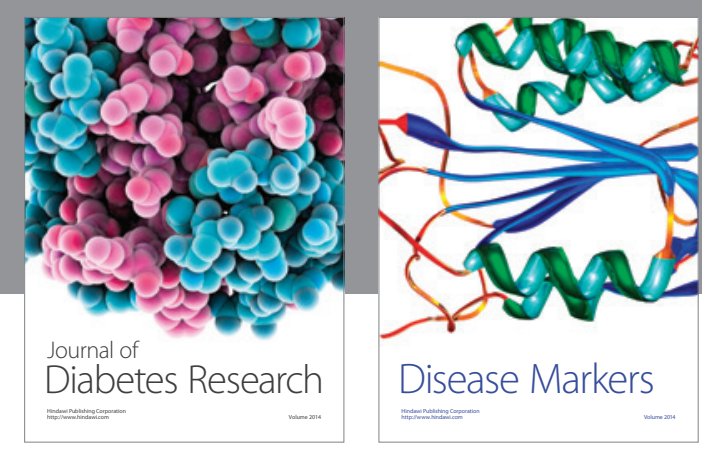

Disease Markers
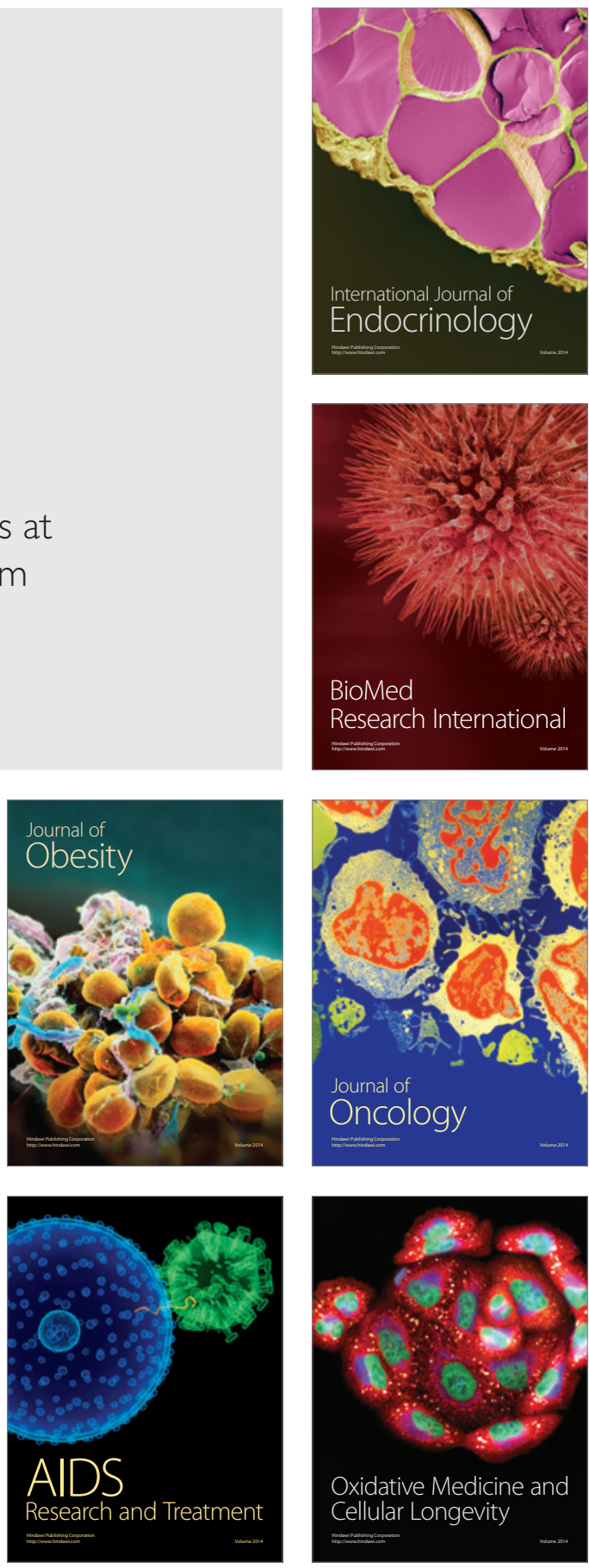